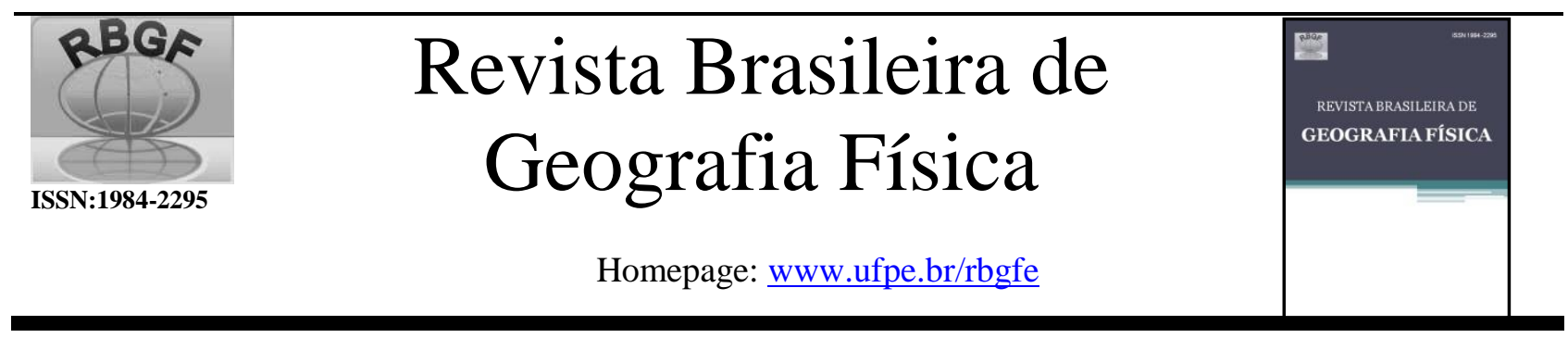

\title{
Vulnerabilidade ambiental dos setores censitários às margens do rio Poti no município de Teresina (Piauí)
}

\author{
Hikaro Kayo de Brito Nunes. E-mail: hikarobrito@gmail.com. Mestre em Geografia (UFPI) e \\ Professor Substituto da Universidade Estadual do Maranhão (UEMA). Cláudia Maria Sabóia de \\ Aquino. E-mail: cmsaboia@ gmail.com. Doutora em Geografia (UFS) e Professora Adjunta da \\ Universidade Federal do Piauí (UFPI).
}

Artigo recebido em 31/10/2017 e aceito em 16/07/2018

\begin{abstract}
R E S U M O
A sociedade atual vive exposta a uma infinidade de problemas ambientais de modo que estes veiculam características que geram danos à população e ao ambiente direta e indiretamente envolvidos. Diante disso, estudos sobre a vulnerabilidade ambiental tornam-se importantes instrumentos de estudo do espaço geográfico em questão, além de contribuir para o planejamento por meio de uma análise integrada entre aspectos sociais e ambientais. Nesse sentido, o objetivo deste estudo foi analisar a vulnerabilidade ambiental dos setores censitários às margens do rio Poti no município de Teresina/Piauí. Como recursos metodológicos podem ser citados: levantamento e análise teórico-conceitual, documental e cartográfica, incursões a área de estudo, utilização do Método Expedito, de Check-list, atividades laboratoriais, uso de softwares com QGis e Google Earth Pro, destaca-se ainda o tratamento estatístico (por meio da Análise Multivariada e Fatorial, além da Técnica de Cluster) dos dados relacionados aos 72 setores censitários e às 12 variáveis ambientais. Os resultados indicaram: 21 setores censitários caracterizados como de vulnerabilidade ambiental Baixa, seguido de 27 e 24 setores censitários com vulnerabilidade ambiental Média e Alta, respectivamente. Os valores obtidos e o enquadramento dos setores por classes deve-se principalmente às notas atribuídas às seguintes variáveis: cobertura vegetal, proximidade com corpos hídricos, adensamento populacional, e esgoto e lixo a céu aberto.

Palavras-chave: vulnerabilidade ambiental; setores censitários; rio Poti; Teresina/Piauí.
\end{abstract}

\section{Environmental vulnerability of the census tracts on the banks of the Poti River in the municipality of Teresina (Piauí)}

\begin{abstract}
A B S T R A C T
Today's society is exposed to a multitude of environmental problems, so that they convey characteristics that generate damage to the population and the environment directly and indirectly involved. Therefore, studies on environmental vulnerability become important tools for studying the geographical space in question, besides contributing to the planning through an integrated analysis between social and environmental aspects. In this sense, the objective of this study was to analyze the environmental vulnerability of the census tracts on the banks of the Poti River in the municipality of Teresina / Piauí. As methodological resources can be cited: survey and theoretical-conceptual analysis, documentation and cartographic, incursions into the study area, use of Expedito Method, Checklist, laboratory activities, use of software with QGis and Google Earth Pro, the statistical treatment (through the Multivariate and Factorial Analysis, as well as the Cluster Technique) of the data related to the 72 census sectors and the 12 environmental variables is also highlighted. The results indicated: 21 census tracts characterized as low environmental vulnerability, followed by 27 and 24 census tracts with medium and high environmental vulnerability, respectively. The values obtained and the classification of the sectors of classes are mainly due to the grades attributed to the following variables: vegetal cover, proximity to water bodies, population density, and sewage and garbage in the open.
\end{abstract}

Keywords: Environmental Vulnerability; Census Tracts; Poti River; Teresina / Piauí.

\section{Introdução}

Nos últimos decênios constatou-se um significativo aumento das discussões acerca dos problemas ambientais, principalmente originados por ações antrópicas. Estudos demonstram que em áreas urbanas o grau de magnitude dos problemas 
ambientais conferem a esses espaços uma criação e intensificação da vulnerabilidade ambiental, haja vista a própria limitação do ambiente somado às ações antropogênicas.

O termo ambiental na visão de Suertegaray (2015) indica a compreensão do sujeito na relação com o meio em que está inserido. Depois da década de 1970, com o início dos debates mundiais em torno da temática ambiental, não só a Geografia, mas as ciências de maneira geral se debruça na temática, os geógrafos, por exemplo, "conceberam Geografia como a ciência da relação Homem e Natureza ou Natureza e Sociedade (ciência de síntese ou ponte)" (Suertegaray, 2017, p. 96).

Ainda no caso da ciência geográfica, foi observado uma aproximação da ciência com as temáticas ambientais, e, consequentemente, da problemática ambiental, ao passo de que as problemáticas ambientais resultante do capitalismo "levaram surgimento de movimentos sociais preocupados com a qualidade de vida das pessoas e do meio ambiente" (Morais e Melo, 2013, p. 26).

Nessa discussão, a organização da sociedade contemporânea deriva e se apropria do meio natural principalmente por meio do capitalismo como processo econômico e de progresso. Isto posto, infere-se que a percepção da paisagem para a análise da organização espacial sustenta-se na utilização de um enfoque de três sistemas (natureza, economia e população) que, mesmo autônomos, são vistos de forma integrada e sistêmica. Assim, a ação antrópica no ambiente provoca complexas mudanças nos elementos que compõem a paisagem, e, dentro dessa perspectiva, a da expansão da sociedade sobre os espaços vai de encontro a ideia da preservação ambiental.

Deste modo, compreender a vulnerabilidade de determinada área ou grupo social, torna-se um importante instrumento para políticas e ações distintas. Considera-se também o fato do conceito de vulnerabilidade ser detentor de uma multidimensionalidade englobando diversas temáticas a exemplo dos riscos e da resiliência.

No que se refere à vulnerabilidade ambiental, esta é caracterizada como a relação relação intrínseca de variados processos mediante a relação entre o homem e a natureza exige $o$ conhecimento dos padrões de vulnerabilidade, considerando a fragilidade dos ecossistemas e a vulnerabilidade devido a fatores endógenos e exógenos (Lourenço, et al, 2013; Santos, 2015). Enquanto Medeiros e Souza (2016) afirmam que a vulnerabilidade ambiental refere-se ao conjunto integrado de fatores ambientais (ecológicos e biológicos), que, diante de atividades humanas, ocorrentes ou que venham se manifestar, poderá sofrer alterações afetando, total ou parcialmente, a estabilidade ecológica de um local.

Nesse contexto, o presente estudo teve como objetivo analisar a vulnerabilidade ambiental dos setores censitários às margens do rio Poti no município de Teresina/Piauí. Ressalta-se a utilização da unidade espacial (setores censitários) por abranger tanto a zona urbana quanto a zona rural, além dos resultados satisfatórios no emprego desta unidade alcançados por Alcântara, Strauch e Ajara (2013), Freitas e Cunha (2013), Medeiros e Souza (2016), Ribeiro e Vóvio (2017) e Silva et al (2017) em distintos municípios brasileiros.

Segundo IBGE (2017), setores censitários correspondem a unidade territorial estabelecida para fins de controle cadastral, formado por área, situada em um único quadro urbano ou rural.

\section{Material e métodos}

A pesquisa que se segue fez uso do Método Dedutivo e abordagem quali-quantitativa, visto que os fenômenos não podem ser explicados sem uma teoria geral para a compreensão de um fato particular por meio do racionalismo. Para alcançar o objetivo, fez-se necessário os seguintes procedimentos: levantamento bibliográfico, teórico-conceitual, documental e cartográfico; reconhecimento da área de estudo (com utilização de diário de campo); atividades de gabinete e de campo (identificação de problemas ambientais); registro fotográfico; recorte espacial da área de estudo; utilização do geoprocesamento e da estatística dentre outros que mostraram-se eficientes para o desenvolvimento da pesquisa. As etapas metodológicas expostas na figura 01. 
Revista Brasileira de Geografia Física v.11, n.06 (2018) 1941-1962

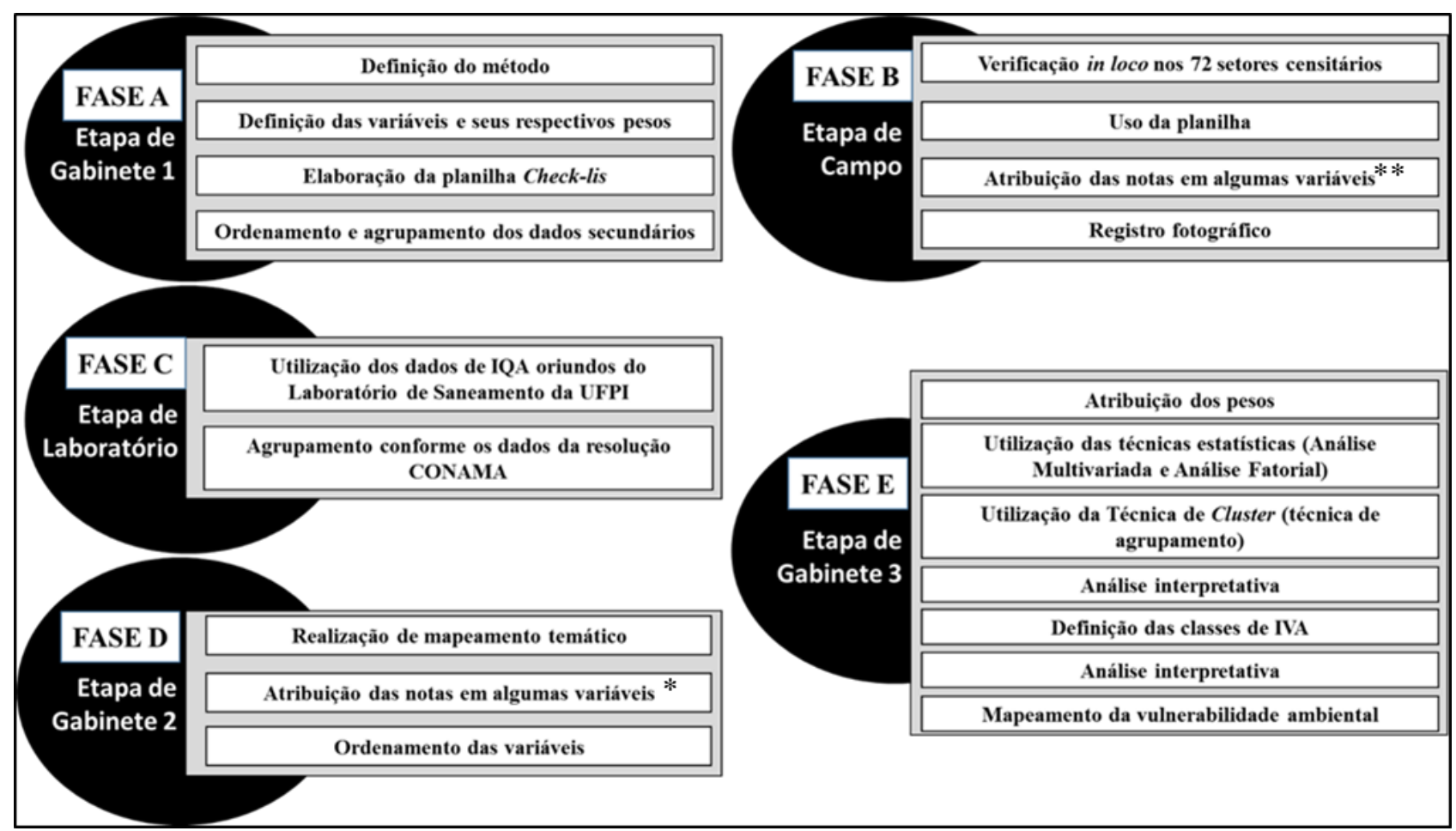

(*) Cobertura vegetal, corpos hídricos, adensamento populacional/residencial, inundação, alagamento e movimento de massas. (**) Situação de conservação/respeito à APP do rio Poti, área de mineração, presença de bancos de areia, lixo a céu aberto e esgoto a céu aberto.

Para a obtenção dos dados relacionados ao Índice de Vulnerabilidade Ambiental (IVA), fez-se uso da quantificação dos problemas e riscos ambientais situados em cada setor censitário por meio do Método Expedito. O referido método pauta-se na verificação in loco de determinado problema ou característica de forma subjetiva por meio de variáveis ordenadas, facilitando o ordenamento e mensuração em campo (nos aspectos quantitativos e qualitativos), instrumentalizado por Check-list, de modo a contribuir com a possibilidade de indicações de cenários favoráveis e desfavoráveis do meio.

Sobre o Check-list, Cremonez et al (2014) argumentam que é um método onde há relações padronizadas de fatores ambientais a partir das quais identificam-se os impactos provocados por algum fato ou fenômeno. A referida aplicação constou do preenchimento de uma planilha de observação (ou listagem de observação) de modo a buscar compreender as variáveis ambientais selecionadas.

Soma-se ao Método Dedutivo e ao Checklist o tratamento estatístico por meio da Análise Multivariada (caracterizada pela análise de um conjunto de variáveis relacionadas ao mesmo objeto), da Análise Fatorial (onde há a redução dos valores das variáveis sem prejuízo para o tratamento estatístico) e da Técnica de Cluster (ou Técnica de Agrupamento, sendo caracterizada pela classificação de elementos heterogêneos em diferentes classes homogêneas).

Torna-se oportuno destacar que os riscos e problemas ambientais não se caracterizam somente pela capacidade de suporte dos recursos naturais, mas também pela espacialização desses fenômenos e pela interação desses com os grupos sociais, vale ressaltar também que o Método Expedito é um importante instrumento quali-quantitativo de qualidade e vulnerabilidade ambiental, como salientam Moraes et al. (2016).

Diante do exposto, o estudo considerou o olhar empírico (pautado no Método Expedito), a utilização de imagens de satélite e análises laboratoriais e documentais com vistas a compreender a dinâmica das 12 variáveis ambientais, tais como: cobertura vegetal, proximidade com corpos hídricos, situação de conservação/respeito à APP do rio Poti, adensamento populacional/residencial, área de mineração, presença de bancos de areia, qualidade da água, lixo a céu aberto, esgoto a céu aberto, inundação, alagamento e movimento de massas, conforme exposto no Quadro 01.

Ressalta-se que a qualidade da água se deu por meio do Índice de Qualidade da Água (IQA) por meio de monitoramento realizado pelo Laboratório de Saneamento (LASAM) do Centro de Tecnologia (CT) da Universidade Federal do Piauí (UFPI). 
Quadro 01 - Variáveis e pesos utilizados para a obtenção do Índice de Vulnerabilidade Ambiental (IVA)

\begin{tabular}{|c|c|}
\hline $\begin{array}{l}\text { CÓDIGO DAS } \\
\text { VARIÁVEIS }\end{array}$ & DESCRIÇÃO \\
\hline $\begin{array}{l}\text { Variável } 1 \text { (V1) } \\
\text { Cobertura vegetal }\end{array}$ & $\begin{array}{l}\text { A cobertura vegetal é importante para a proteção contra os processos erosivos, e para } \\
\text { a contenção das ribanceiras dos rios, além no auxílio no conforto térmico em áreas } \\
\text { urbanas. [PESOS: Baixa (menos de } 30 \% \text { do setor) = 3. Média (entre 30\% e } 70 \% \text { do } \\
\text { setor) }=2 \text {. Alta (acima de } 70 \% \text { do setor) }=1]\end{array}$ \\
\hline $\begin{array}{l}\text { Variável } 2 \text { (V2) } \\
\text { Proximidade com } \\
\text { corpos hídricos }\end{array}$ & $\begin{array}{l}\text { Os corpos hídricos são ambientes vulneráveis naturalmente e com intensidade } \\
\text { acrescida com o avanço da ocupação humana, seja em áreas rurais quanto urbanas. } \\
\text { Fenômenos e processos como enchentes, inundações, veiculação hídrica, } \\
\text { assoreamento e processos erosivos são atuantes nessa variável. [PESOS: Baixa } \\
\text { (somente o rio Poti) }=1 \text {. Média (Rio Poti e riacho ou lagoa) }=2 \text {. Alta (Rio Poti, } \\
\text { riachos e lagoas })=3 \text {. Muito Alta (rios Poti e Parnaíba) }=4 \text { ] }\end{array}$ \\
\hline $\begin{array}{l}\text { Variável } 3(\mathbf{V 3}) \\
\text { Situação de } \\
\text { conservação/ respeito } \\
\text { à APP do rio Poti }\end{array}$ & $\begin{array}{l}\text { Essa variável articula-se com o a Lei } N^{\circ} 12.651 \text { ("Novo" Código Florestal) e } \\
\text { demonstra a respeitabilidade das APPs do rio Poti frente a ocupação urbana e } \\
\text { atividades produtivas. [PESOS: Boa (atendimento a legislação) }=1 \text {. Regular } \\
\text { (atendimento básico da legislação) }=2 \text {. Ruim (sem atendimento a legislação) }=3 \text { ] }\end{array}$ \\
\hline $\begin{array}{l}\text { Variável } 4(\mathbf{V 4}) \\
\text { Adensamento } \\
\text { populacional/ } \\
\text { residencial }\end{array}$ & $\begin{array}{l}\text { Relaciona-se com a distribuição e nível de ocupação em cada setor censitário, além } \\
\text { de ajudar a identificar os setores que estão potencializando a vulnerabilidade } \\
\text { ambiental. [PESOS: Baixa (menos de } 30 \% \text { do setor) }=1 \text {. Média (entre } 30 \% \text { e } 70 \% \\
\text { do setor) }=2 \text {. Alta (acima de } 70 \% \text { do setor) }=3 \text { ] }\end{array}$ \\
\hline $\begin{array}{l}\text { Variável } 5 \text { (V5) } \\
\text { Área de mineração }\end{array}$ & $\begin{array}{l}\text { Essa atividade gera degradação ambiental e transtornos a população que mora no } \\
\text { entorno. Alguns impactos são: produção de poeira, ruído, poluição da água, risco a } \\
\text { saúde humana, aumento do fluxo de caminhões. [PESOS: Existente = 1. Inexistente } \\
=0 \text { ] }\end{array}$ \\
\hline $\begin{array}{c}\text { Variável 6(V6) } \\
\text { Presença de bancos } \\
\text { de areia }\end{array}$ & $\begin{array}{l}\text { Caracterizado como depósito de material aluvionar. Sua formação é a partir do } \\
\text { transporte natural de sedimentos, entretanto, quando da ocupação desordenada das } \\
\text { áreas marginais e retirada da vegetação há um aumento do carreamento de material } \\
\text { para os rios e, quando da sua acumulação, formam-se bancos de areia com tamanho } \\
\text { e forma variadas. [PESOS: Presente }=1 \text {. Ausente }=0 \text { ] }\end{array}$ \\
\hline $\begin{array}{l}\text { Variável } 7 \text { (V7) } \\
\text { Qualidade da água }\end{array}$ & $\begin{array}{l}\text { A qualidade da água é reflexo das formas de uso, ocupação e cobertura da terra, além } \\
\text { da topografia, geologia, clima e cobertura vegetal. Acrescenta-se que o uso } \\
\text { inadequado de áreas ribeirinhas acarreta a contaminação da água comprometendo } \\
\text { suas características químicas, físicas e biológicas. [PESOS: Muito ruim (entre } 0 \text { e } 19 \\
\text { no IQA) }=5 \text {. Ruim (entre } 20 \text { e } 36 \text { no IQA) }=4 \text {. Regular (entre } 37 \text { e } 51 \text { no IQA) }=3 \text {. } \\
\text { Bom (entre } 52 \text { e } 79 \text { no IQA) }=2 \text {. Excelente (entre } 80 \text { e } 100 \text { no IQA) }=1 \text {.] }\end{array}$ \\
\hline $\begin{array}{c}\text { Variável } 8 \text { (V8) } \\
\text { Lixo a céu aberto } \\
\text { Variável } 9(\mathbf{V 9 )} \\
\text { Esgoto a céu aberto }\end{array}$ & $\begin{array}{l}\text { Associado a questão de saneamento básico, essas variáveis, quando encontradas, } \\
\text { evidenciam o grau de exposição dos moradores a riscos ambientais e de saúde } \\
\text { pública. [PESOS: Pouco visível }=1 \text {. Em alguns pontos }=2 \text {. Facilmente visível =3] }\end{array}$ \\
\hline $\begin{array}{c}\text { Variável 10 (V10) } \\
\text { Inundação } \\
\text { Variável 11 (V11) } \\
\text { Alagamento } \\
\text { Variável 12 (V12) } \\
\text { Movimento de } \\
\text { massas } \\
\end{array}$ & $\begin{array}{l}\text { Essas variáveis estão associadas a dinâmica natural e as formas de ocupação do } \\
\text { espaço geográfico, principalmente quando da ocupação de áreas ribeirinhas e áreas } \\
\text { de encostas. Diante disso, esse cenário gera riscos e problemas ambientais de modo } \\
\text { que há a intensificação da vulnerabilidade ambiental presente na área. [PESOS: } \\
\text { Ausente }=0 \text {. Presente }=1 \text { ]. }\end{array}$ \\
\hline
\end{tabular}

O tratamento das variáveis de vulnerabilidade ambiental baseou-se em atividades de gabinete (utilização do sensoriamento remoto e análise documental), atividades de laboratório (com dados do LASAM/UFPI) e atividades de campo instrumentalizada com check-list. Para a confecção desse índice fez-se necessário o emprego de mapas temáticos (base cartográfica ambiental em formato vetorial e raster) e posteriormente manipulação de softwares para a classificação e atribuição de valores em relação ao grau e vulnerabilidade ambiental. 
Sobre o mapa de uso, ocupação e cobertura da terra, houve seleção da imagem datada do mês de março de 2017 (órbita 219 e ponto 64) levando em consideração a pouca quantidade de nuvens para melhor tratamento e interpretação da imagem, seguido do download (no dia 26/07/2017) da imagem oriunda do satélite Landsat 8 disponibilizada pelo site do United States Geological Survey (USGS) com acesso no https://earthexplorer.usgs.gov/ e uso das bandas 4, 3 e 2 .

Empregou-se a classificação nãosupervisionada usando o software QGis e conforme IBGE (2013). As área de lagoas foram obtidas por meio de vetorização através do Google Earth Pro.

Quanto ao mapa de vulnerabilidade ambiental, este apoiou-se no Método Expedito, já explicitado. Ao fim da etapa de tabulação dos dados e atribuição dos respectivos pesos de acordo com os setores censitários e as variáveis ambientais, procedeu-se a soma de todas as variáveis por setor e o agrupamento por classes do Índice de Vulnerabilidade Ambiental (IVA), em "Alta", "Média" e "Baixa", conforme tabela 10. As notas variaram no intervalo compreendido entre 13 e 23 na escala do IVA.

A base de dados cartográficos foi construída por meio de pesquisas realizadas na Empresa Brasileira de Pesquisa Agropecuária (EMBRAPA), Centro de Pesquisa de Recursos Minerais (CPRM), Instituto Nacional de Pesquisas Espaciais (INPE), Instituto Brasileiro de Geografia e Estatística (IBGE) e Agência Nacional de Águas (ANA).

\section{Resultados e discussão}

\section{A área de estudo: localização e delimitação censitária}

No município de Teresina é onde o rio Poti entra em contato com a maior pressão antrópica, motivada pela urbanização durante todo o seu curso, e, nesse sentido, a área de investigação engloba tanto a zona urbana quanto a zona rural por onde passa o canal do rio Poti (figura 02).

Os setores censitários dos bairros estudados consta no quadro 02, conforme IBGE 2010.

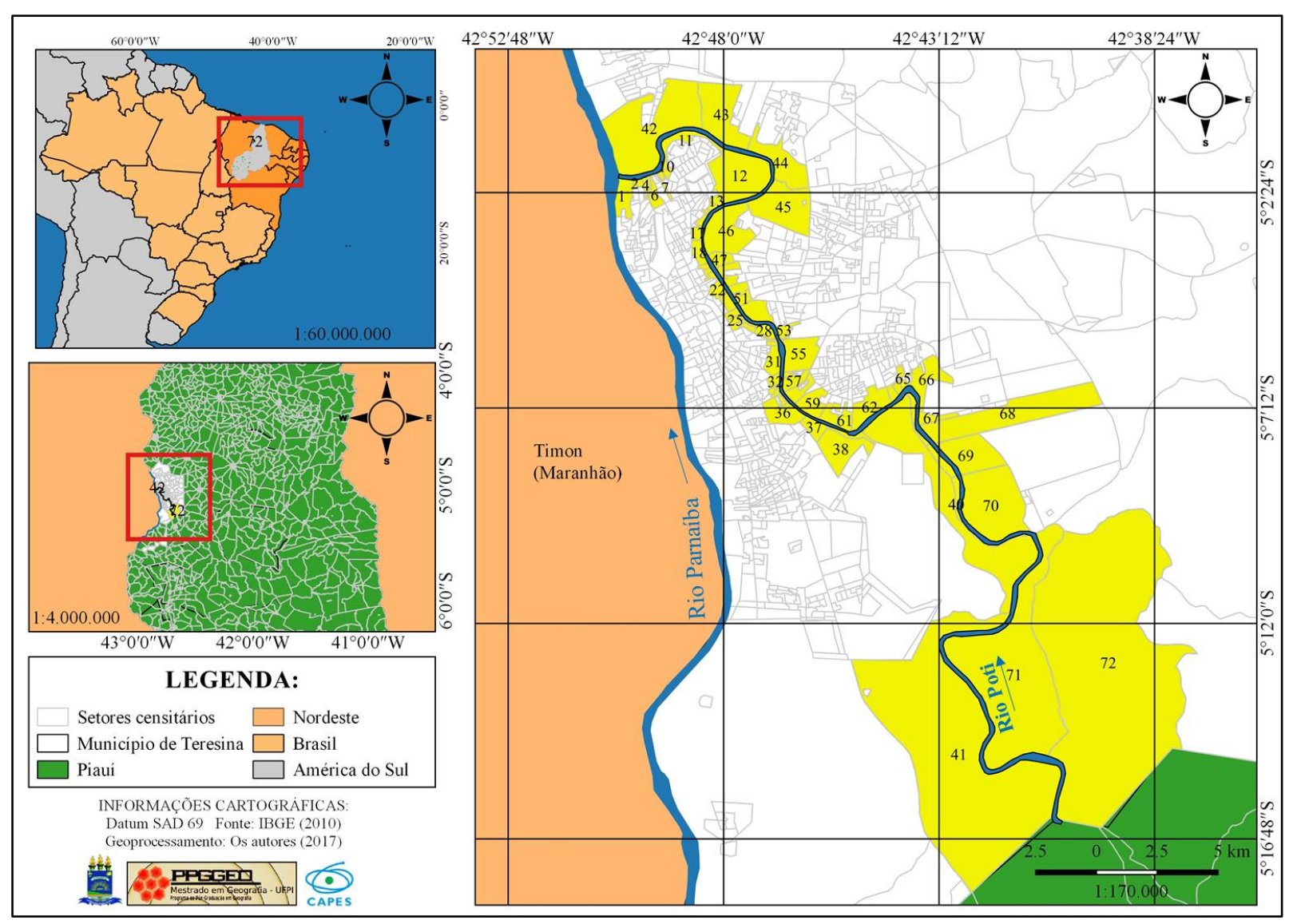

Figura 02 - Localização da área de estudo

Quadro 02 - Espacialização dos setores censitários por bairros (zona urbana de Teresina)

\begin{tabular}{|c|l|c|c|c|c|}
\hline Setor (es) & Bairro (s) & Setor (es) & Bairro (s) & Setor (es) & Bairro (s) \\
\hline 01 & Olarias & 30 e 31 & Cristo Rei & 52 & Noivos \\
\hline
\end{tabular}


Revista Brasileira de Geografia Física v.11, n.06 (2018) 1941-1962

\begin{tabular}{|c|l|c|l|c|l|}
\hline $02,03,04$ e 05 & Poti Velho & 32,33 e 34 & Três Andares & 53 e 54 & São João \\
\hline 06 e 07 & Alto Alegre & 35 e 36 & Catarina & 55 & São Raimundo \\
\hline 08,09 e 10 & São Francisco & 37 & São Lourenço & 56 e 57 & Beira Rio \\
\hline 11 & Mocambinho & 38,39 e 40 & Santo Antônio & 58 & Tancredo Neves \\
\hline 12 & Embrapa & $41^{*}$ & $\begin{array}{l}\text { Zona rural (margem } \\
\text { esquerda) }\end{array}$ & 59 & Comprida \\
\hline $\begin{array}{c}13,14,15,16 \text { e } \\
17\end{array}$ & Água Mineral & 42 & Santa Rosa & 60 e 61 & Extrema \\
\hline 18 e 19 & Primavera & 43 & Aroeiras & 62 & Redonda \\
\hline 20 e 21 & Morro da Esperança & 44 & Pedra Mole & 63 e 64 & Parque Poti \\
\hline 22 & Porenquanto & 45 & Zoobotânico & 65 e 66 & São Sebastião \\
\hline 23 & Cabral & 46 & Ininga & 67 & Bom Princípio \\
\hline 24 e 25 & Frei Serafim & 47,48 e 49 & Fátima & $68^{*}, 69^{*}, 70^{*}$, & $\begin{array}{l}\text { Zona rural } \\
\text { (margem direita) }\end{array}$ \\
\hline $26,27,28$ e 29 & Ilhotas & 50 e 51 & Jóquei & & \multicolumn{2}{c}{ e 72* } \\
\hline
\end{tabular}

Caracterização das variáveis do IVA

O IVA considerou o Método Expedito empregado em uma perspectiva integrada das variáveis (quadro 03) por setor censitário originados a partir das etapas de campo e de gabinete.

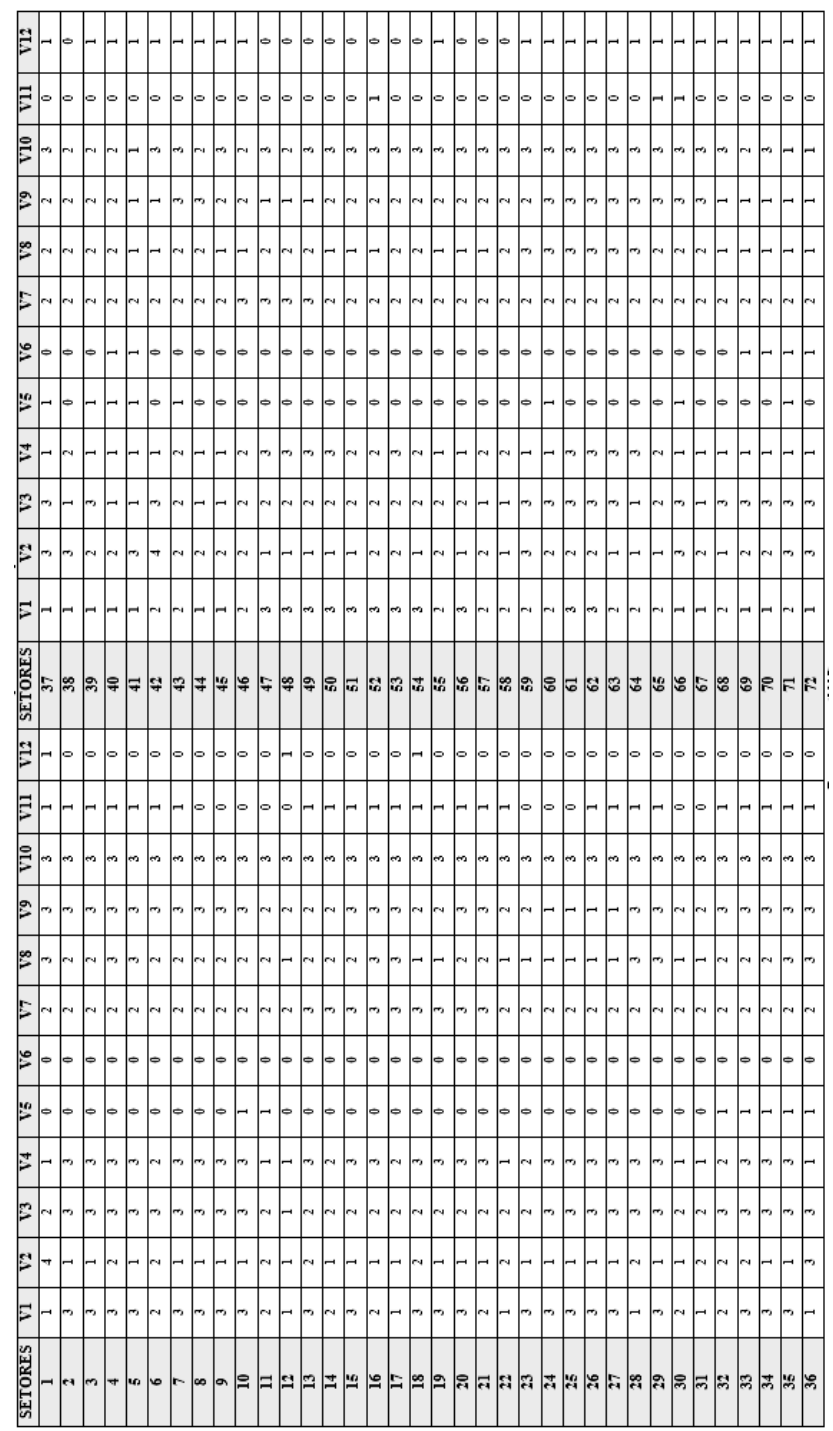

Quadro 03 - Resultado das variáveis ambientais por setores censitários

Sobre a variável 1 (Cobertura vegeral), Lima et al (2013) e França et al (2018) afirmam que elevadas densidades de cobertura vegetal tendem para um ambiente de estabilidade, diante disso, com uso do sensoriamento remoto, geoprocessamento, atividades de campo e técnicas 
de estatística, os setores foram identificados de acordo com a densidade vegetal. Como era esperado, os setores localizados na zona rural de Teresina obtiveram os valores mais significativos no que se refere ao adensamento dessa cobertura, ante aos setores localizados na zona urbana.

Torna-se necessário afirmar que a área de estudo está disposta em aproximadamente 20.276 hectares e corresponde a aproximadamente 14,7\% da área do município de Teresina. Sobre a área de estudo, e, conforme o Manual de Uso da Terra desenvolvido pelo IBGE (2013) foram identificadas 04 classes de uso, ocupação e cobertura da terra representando a multiplicidade e a complexidade da referida área, possibilitando assim uma variedade de interpretações, principalmente no que se refere à cobertura vegetal (tabela 01).

\begin{tabular}{l|c|c}
\multicolumn{1}{c|}{ CLASSES } & VALORES EM & VALORES EM \\
HECTARES (HA) & PORCENTAGEM (\%) \\
\hline Corpos hídricos & 751 & $3,7 \%$ \\
\hline Agricultura/ Vegetação rasteira & 7.152 & $35,3 \%$ \\
\hline Vegetação densa & 6.499 & $32,1 \%$ \\
\hline Área urbana/ Solo exposto/ Superfície impermeável & 5.874 & $28,9 \%$ \\
\hline \multicolumn{1}{c|}{ TOTAL } & $\mathbf{2 0 . 2 7 6}$ ha & $\mathbf{1 0 0 \%}$ \\
\hline
\end{tabular}

Tabela 01 - Valores de uso, ocupação e cobertura da terra da área de estudo com imagem de 2017

As classes definidas para análise dessa variável foram: "baixa" cobertura vegetal (Agricultura/Vegetação rasteira e Vegetação densa), representando $30 \%$ da área de cada setor censitário; "média", entre $30 \%$ e $70 \%$ do setor censitário e "alta", acima de $70 \%$ de cobertura vegetal nos setores censitários. Os pesos foram 3,2 e 1, respectivamente.

Esses valores auxiliam na interpretação da relação entre vulnerabilidade e cobertura vegetal, haja vista a vinculação desta com o processo erosivo, o microclima, a drenagem e outros indicadores correlatos.

$\mathrm{Na}$ classe de "baixa" cobertura vegetal (peso 3) foram encontrados 33 setores censitários, a saber: 2, 3, 4, 5, 7, 8, 9, 10, 13, 15, 18, 19, 20, 23, $24,25,26,27,29,33,34,35,47,48,49,50,51,52$, $53,54,56,61$ e 62 , distribuídos em todas as regiões administrativas da área urbana. Os bairros em que estes setores estão localizados são os seguintes: Poti Velho, Alto Alegre, São Francisco, Água Mineral, Primavera, Morro da Esperança, Cabral, Frei Serafim, Ilhotas, Três Andares e Catarina (localizados na margem esquerda do rio Poti) e Fátima, Jóquei, Noivos, São João, Beira Rio, Extrema e Redonda (na margem direita do Poti).

Na classe de "média" (peso 2) cobertura vegetal, 20 setores censitários $(6,11,14,16,21,30$, $32,42,43,46,55,57,58,59,60,63,64,65,68$ e 71) foram identificados e estão localizados nos seguintes bairros: Alto Alegre, Mocambinho, Água Mineral, Morro da Esperança, Cristo Rei e Três Andares (na margem esquerda do Poti) e Santa Rosa, Aroeiras, Ininga, São Raimundo, Beira Rio,
Tancredo Neves, Comprida, Parque Poti, São Sebastião e parte da zona rural (margem direita do rio).

Na classe de "alta" cobertura vegetal (peso 1) foram identificados 19 setores censitários, são eles: 1, 12, 17, 22, 28, 31, 36, 37, 38, 39, 40, 41, 44, 45, 66, 67, 69, 70 e 72. Distribuídos nos seguintes bairros: Olarias, Embrapa, Água Mineral, Porenquanto, Ilhotas, Cristo Rei, Catarina, São Lourenço, Santo Antônio e a zona rural (da Margem Esquerda/ME do rio Poti) e Pedra Mole, Zoobotânico, São Sebastião, Bom Princípio e parte da zona rural (Margem Direita/MD).

Sobre os setores da zona rural, alguns não foram incluídos (os setores nessa classe por causa das atividades produtivas neles encontradas, como pecuária e agricultura, o que diminui consideravelmente a quantidade de cobertura vegetal além de expor o rio a riscos no que se refere ao baixo adensamento vegetacional nas APPs. O setor 12, por exemplo, abarca o espaço da Empresa Brasileira de Pesquisa Agropecuária (EMBRAPA Meio-Norte) que possui dentro da sua área um significativo adensamento vegetacional. Em termos percentuais, há os seguintes valores para essa variável: $46 \%$ dos setores censitários possuem cobertura vegetal baixa quando relacionados com a área dos mesmos, ante $28 \%$ de setores com cobertura vegetal média e $26 \%$ com cobertura vegetal alta (principalmente aqueles localizados na zona rural).

A figura 03 apresenta a espacialização do uso, ocupação e cobertura da terra na área de estudo. 


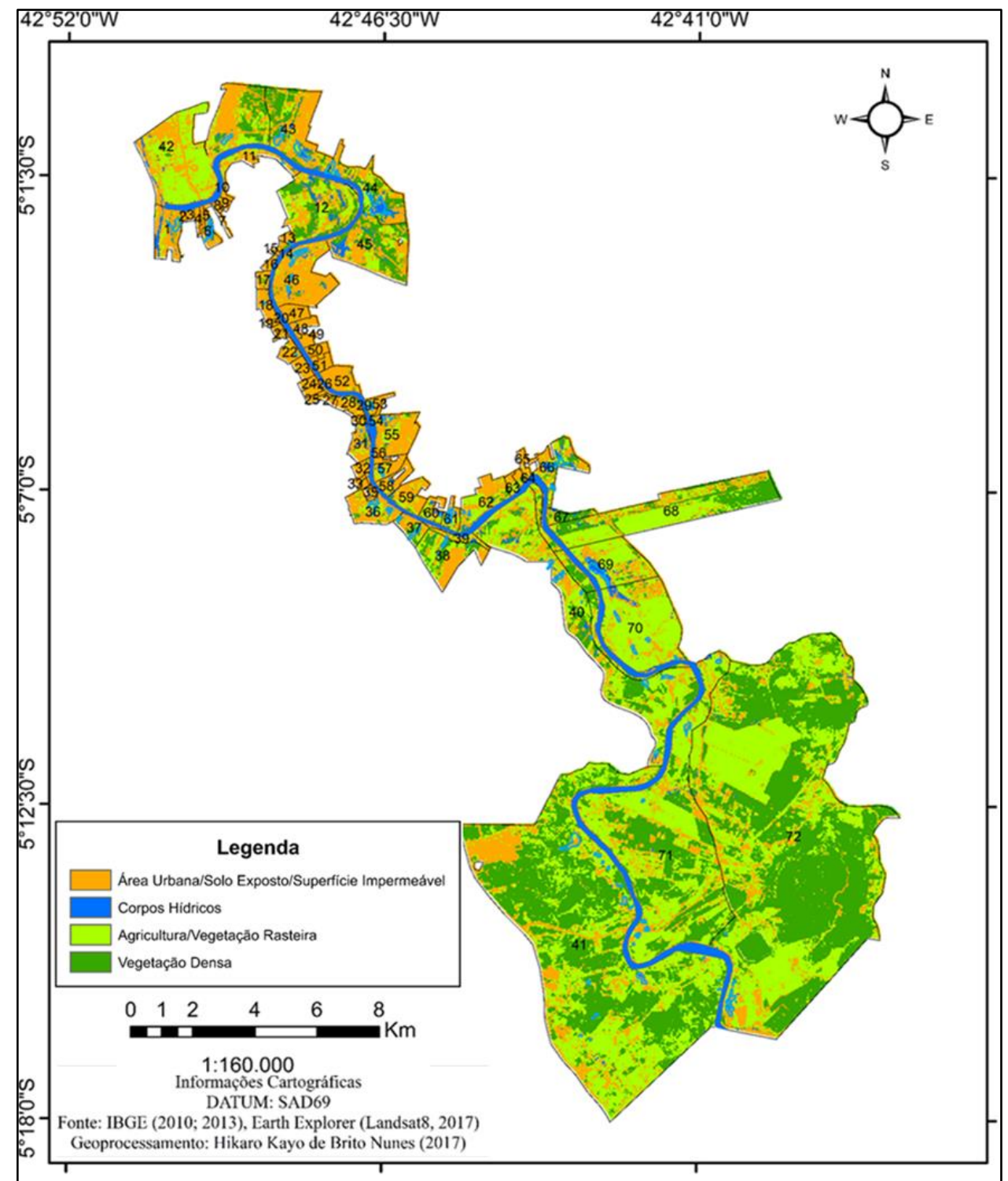

Figura 03 - Mapa de uso, ocupação e cobertura da terra da área de estudo

Sobre a variável 2 (Proximidade com corpos hídricos), foram considerados rios, riachos, lagoas e açudes. A análise foi realizada para os distintos setores censitários objeto deste estudo, sendo que as classes identificadas consideraram a existência de corpos hídricos, e são as seguintes: "baixa", "média", "alta" e "muito alta" com pesos $1,2,3$ e 4 , respectivamente.

$\mathrm{Na}$ classe de existência "baixa" foram identificados 36 setores: 02, 03, 05, 07, 08, 09, 10, $12,14,15,16,17,19,20,21,23,24,25,26,27,29$, 30, 34 e 35 na margem esquerda do Poti, e os setores $47,48,49,50,51,54,56,58,63,64,65$ e 68 na margem direita do rio.

Nesta classe destaca-se o rio Poti (figura 04A), haja vista ser o referencial da área de estudo. Ressalta-se ainda que estes setores estão localizados nos seguintes bairros: Poti Velho, Alto Alegre, São Francisco, Embrapa, Água Mineral,
Primavera, Morro da Esperança, Cabral, Frei Serafim, Ilhotas, Cristo Rei, Três Andares e Catarina (ME) e Fátima, Jóquei, São João, Beira Rio, Parque Poti e São Sebastião (MD), além de um setor na zona rural do município.

A classe de existência "média" compreende a permanência de riachos ou lagoas somados a presença do rio Poti. Nesse caso, o peso 2 foi atribuído a 26 setores, a saber: 04, 06, 11, 13, $18,22,28,31,32,33,39$ e 40 (margem direita) e $43,44,45,46,52,53,55,57,60,61,62,67,69$ e 70 (margem esquerda). Nestes setores são encontrados os seguintes bairros: Poti Velho, Alto Alegre, Mocambinho, Água Mineral, Primavera, Porenquanto, Ilhotas, Cristo Rei, Três Andares e Santo Antônio (ME), além de Aroeiras, Pedra Mole, Zoobotânico, Ininga, Noivos, São João, São Raimundo, Beira Rio, Extrema, Redonda, Bom 
Princípio e dois setores localizados na zona rural (MD) (figura 04B).

Enquadrados na classe de "alta" existência e atribuídos de peso 3, foram identificados oito setores censitários distribuídos quantitativamente de forma igual nas margens esquerda $(36,37,38 \mathrm{e}$ 41) e direita $(59,66,71$ e 72$)$. Os setores acima indicados estão localizados nos bairros Catarina, São Lourenço e Santo Antônio (todos na região Sul de Teresina), além do setor 41, localizado na zona rural. $\mathrm{Na}$ margem direita, estão os bairros Comprida e São Sebastião (figura 04C), localizados na região Sudeste, bem como os setores 71 e 72, situados na zona rural.

A classe de existência "muito alta" (peso 4) considera os rios Poti e Parnaíba (figura 04D). Ressalta-se que os setores 1 (bairro Olarias) e 42 (bairro Santa Rosa) apresentam vulnerabilidade ambiental muito alta considerando os aspectos hidrológicos em razão da existência dos dois rios. Assegura-se ainda o fato que ambos os setores, espacialmente são os pontos mais extremos (a jusante) da área de estudo.

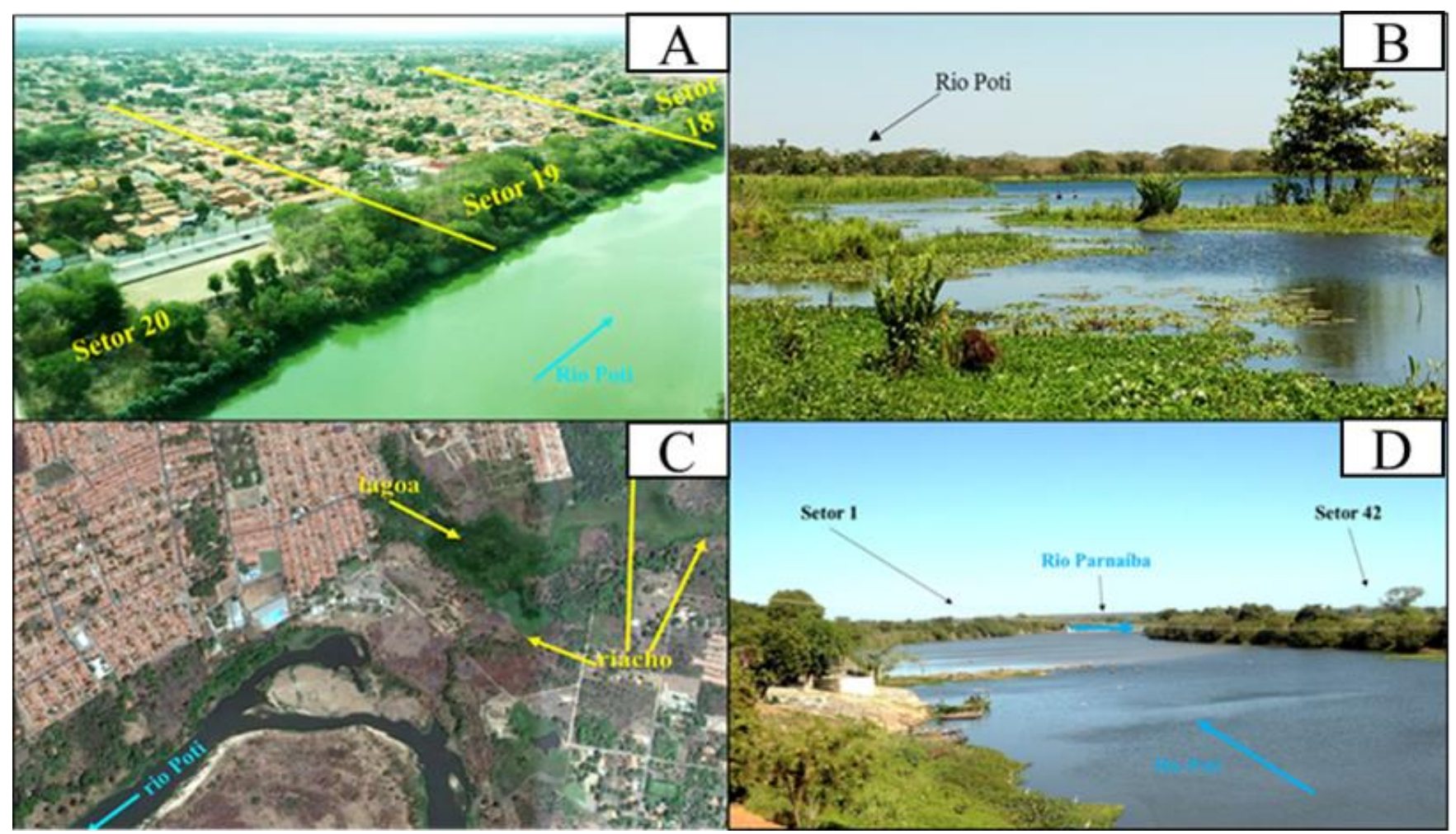

Figura 04 - Setores censitários discutidos por classe da variável 2. Em A, setores 18, 19 e 20; em B, setor 45; em C, setor 66; e em D, setores 1 e 42.

Em síntese, nessa variável estão, 50\% dos setores censitários na classe "baixa", $36 \%$ na classe "média", $11 \%$ como de "alta" existência de corpos hídricos e 3\% na classe "muito alta". Essa variável se articula ainda com os riscos ambientais de enchentes e inundações, haja vista estes setores possuírem quantidade significativa de corpos hídricos.

Na variável que trata da Situação de conservação/respeito à APP do rio Poti (variável 3 ), foram classificados 11 setores censitários (12, $13,38,40,41,44,45,57,58,64$ e 67) como de "boa" situação, distribuídos nos bairros Embrapa, Água Mineral, Santo Antônio, Pedra Mole, Zoobotânico, Beira Rio, Tancredo Neves, Parque Poti, Bom Princípio e áreas da zona rural. Nesses setores há respeitabilidade do limite da APP com ausência de ocupações e atividades produtivas, além da aparente preservação do aspecto vegetacional (figura $05 \mathrm{~A}$ ).

$\mathrm{Na}$ classe de conservação/respeito "regular" foram identificados 28 setores censitários $(1,11,13,14,15,16,17,18,19,20,21,22,23,30$, $31,43,46,47,48,49,50,51,52,53,54,55,56$ e 65) localizados nas seguintes áreas: Olarias, Mocambinho, Água Mineral, Primavera, Morro da Esperança, Porenquanto, Cabral, Cristo Rei, Aroeiras, Ininga, Fátima, Jóquei, Noivos, São João, São Raimundo, Beira Rio e São Sebastião. Nesses setores, parte da APP está em aparente situação de preservação, contudo, principalmente após o limite de 100m há ocupações diversas, como residências, prédios, shoppings centers e atividades primárias (figura 05B). 
$\mathrm{Na}$ classe "ruim" a respeitabilidade dos limites é preocupante, dos 72 setores censitários da área de estudo 33 estão nessa categoria e são localizados em todas as regiões administrativas de Teresina. Os setores são: $2,3,4,5,6,7,8,9,10$, $24,25,26,27,28,29,32,33,34,35,36,37,39,42$, $59,60,61,62,63,66,68,69,70,71$ e 72 que compreendem parte dos seguintes bairros: Poti Velho, Alto Alegre, São Francisco, Frei Serafim, Ilhotas, Três Andares, Catarina, São Lourenço, Santo Antônio, Santa Rosa, Comprida, Extrema, Redonda, Parque Poti, São Sebastião e todos os setores localizados na zona rural à margem direita (figura 05C).

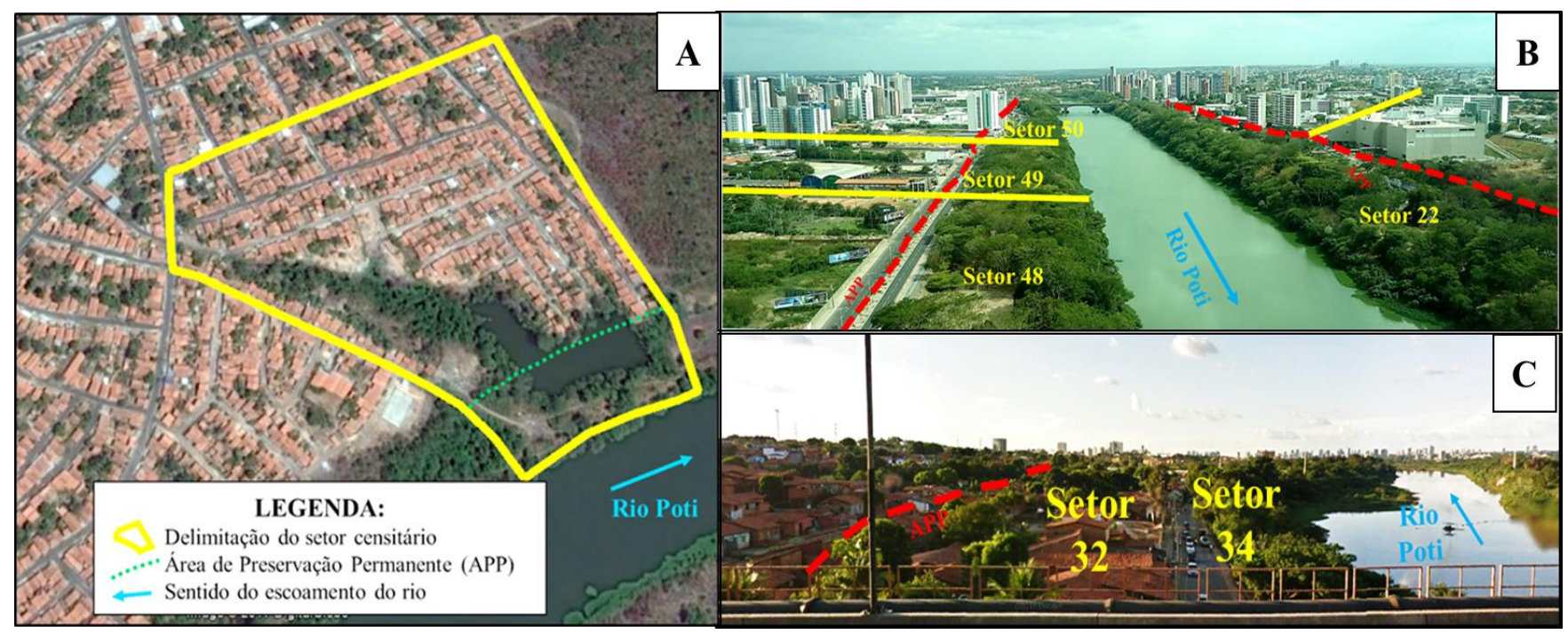

Figura 05 - Respeitabilidade das APP's na área de estudo. Em A, setor 13; em B, setores 22, 48, 49 e 50; e em C, setores 32 e 34.

Ressalta-se, além do mais que a proximidade de edificações e vias de acesso (em alguns trechos com menos de 2 metros de distância) com o rio ocasiona uma diminuição da flora e da fauna, a perca da biodiversidade e da beleza paisagística. Em nível percentual, 15\% dos setores censitários "boa" conservação/respeito da APP, ante $39 \%$ e $46 \%$ das classes "regular" e "ruim", respectivamente.

Sobre o Adensamento populacional/ residencial (variável 4), na classe "baixa" (peso 1) foram encontrados 25 setores censitários, a saber: $1,11,12,22,30,31,36,37,39,40$ e 41 (ME do rio Poti) e 42, 44, 45, 55, 56, 59, 60, 66, 67, 68, 69, 70, 71 e 72 (MD do rio Poti). Estes setores integram os seguintes bairros: Olarias, Mocambinho, Embrapa, Porenquanto, Cristo Rei, Catarina, São Lourenço e Santo Antônio (margem esquerda).

Além dos bairros localizados na margem direita, como: Santa Rosa, Pedra Mole, Zoobotânico, São Raimundo, Beira Rio, Comprida, Extrema, São Sebastião e Comprida. Ressalta-se que todos setores censitários localizados na zona rural foram enquadrados nessa classe da variável. Como exemplo dessa tipologia está o setor 37 (figura 06A) onde há uma quantidade relativamente baixa de ocupações urbanas, o que facilita o escoamento e infiltração da água.

$\mathrm{Na}$ classe "média" (peso 2) foram encontrados 14 setores censitários, a saber: 6, 14, $17,23,32$ e 38 (margem esquerda) e 43, 46, 51, 52, $54,57,58$ e 65 (margem direita). Os bairros em que os mesmos estão inseridos são os seguintes: Alto Alegre (figura 06B), Água Mineral, Porenquanto, Cabral, Três Andares, Santo Antônio, Aroeiras, Ininga, Jóquei, Noivos, São João, Beira Rio, Tancredo Neves e São Sebastião, estando localizados em todas as regiões administrativas da sede do município.

Os setores enquadrados como de "alto" adensamento populacional/ residencial totalizam 33 setores, sendo os seguintes: 2, 3, 4, 5, 7, 8, 9, 10, $13,15,16,18,19,20,21,24,25,26,27,28,29,33$, 34 e 35 (localizados na margem esquerda) e 47, 48, 49, 50, 53, 61, 62, 63 e 64 (localizados na margem direita). Os mesmos estão situados nos seguintes bairros: Poti Velho, Alto Alegre, São Francisco, Água Mineral, Primavera, Morro da Esperança, Frei Serafim, Ilhotas, Três Andares, Catarina, Fátima, Jóquei (figura 06C), São João, Extrema, Redonda e Parque Poti. 


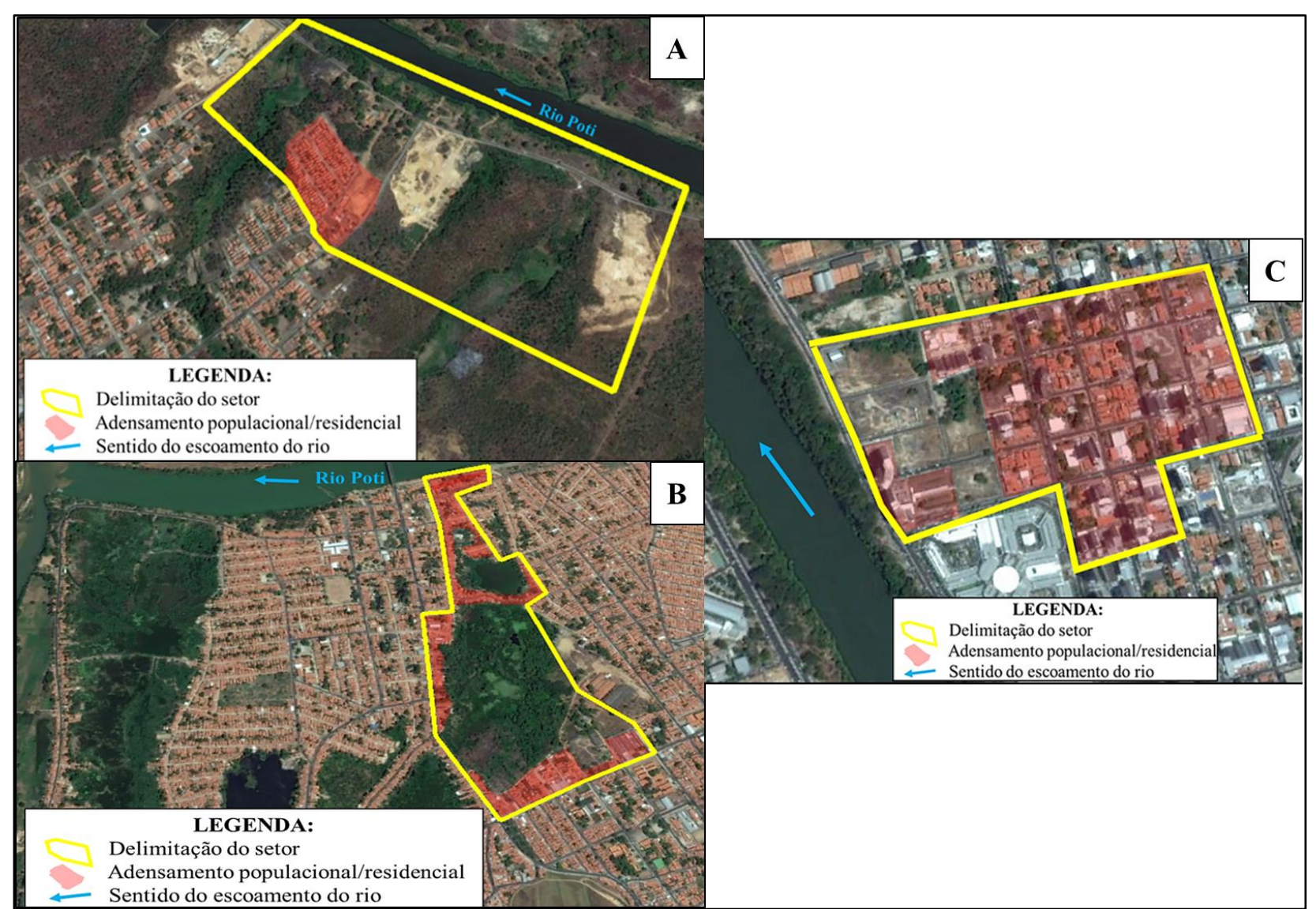

Figura 06 - Classes da variável de adensamento populacional/residencial. Em A, setor 37; em B, setor 6; e em C, setor 50 .

Em termos gerais, $35 \%$ dos setores foram enquadrados na classe de adensamento populacional/residencial "baixo", seguido de $19 \%$ com a classe de "médio" adensamento populacional/residencial e $46 \%$ de "alto" adensamento populacional/residencial, conforme espacialização visualizada na figura 54. Esses valores estão relacionados ainda com o grau de ocupação da área, além de inferir quais setores são mais propícios a grandes danos (ou fenômenos) ambientais e os que poderão ter o maior número de consequência negativa no aspecto socioeconômico.

Sobre a Atividade de mineração (variável 5), em Teresina, de acordo com Pfaltzgraff (2010), os minerais mais comumente extraídos são: calcário, argila, granito, diabásio, areia, seixo e massará. Na área de estudo destaca-se a mineração de seixos, areias, argilas e massarás para a construção civil e indústria cerâmica causando intensos problemas ambientais.

Nessa variável (atividades de mineração ) os setores censitários foram agrupados em duas classes "existente" (peso 1) e "inexistente" (peso $0)$. Foram identificados com base em análise de imagens de satélite e atividades de campo 15 setores censitários onde há extração mineral, a saber: 10, 11, 32, 33, 34, 35, 36, 37, 39, 40, 41 (localizados na margem esquerda) e 43, 60, 66 e 71 (localizados na margem direita). Os bairros onde estão localizados são os seguintes: São Francisco, Mocambinho, Três Andares, Catarina, São Lourenço, Santo Antônio e parte da zona Rural (margem esquerda) e os bairros Comprida e São Sebastião localizados na margem direita, além de áreas da zona Rural nessa margem (figura 07). É necessário ressaltar que há concentração de áreas de mineração na região Sul, perfazendo os bairros Catarina, São Lourenço e Santo Antônio.

A atividade de mineração atinge várias esferas (física, biótica e antrópica) de forma integrada e conflituosa. Nesse sentido, há preocupantes casos na relação sociedade e natureza como forma de conflito ambiental, como os conflitos estudados por Viana (2015), Viana et al (2015) e Vieira e Viana (2016) tendo como locus de estudo a cidade de Teresina.

Vale ressaltar que a vulnerabilidade ambiental decorrente da atividade de mineração é crítica nos setores apontados na figura 06 (espacialização da atividade mineradora na área de estudo), haja vista o processo degradacional neles existentes. Cabe ressaltar ainda que cerca de $21 \%$ dos setores censitários possui características de 
vulnerabilidade ambiental diretamente relacionadas a essa atividade produtiva.

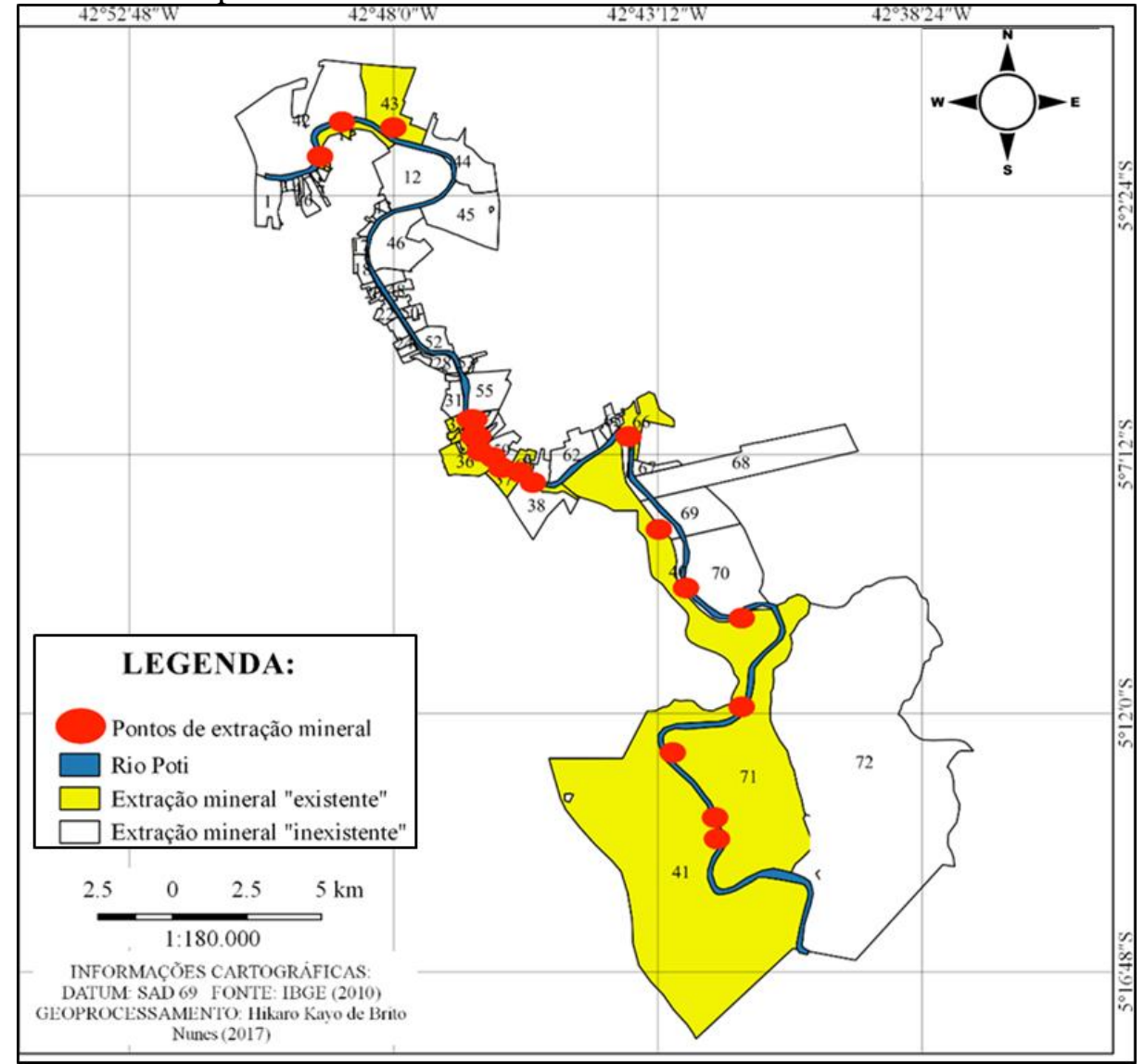

Figura 07 - Mapa da espacialização da atividade mineradora na área de estudo

Na variável 6 (Presença de bancos de areia), os setores censitários foram divididos em dois grupos, bancos de areia "ausente" (peso 0) e "presente" (peso 1). Os bancos de areia foram identificados através de imagens de satélite e expedições in loco em seis setores censitários, a saber: $69,70,71$ e 72 , na margem direita, e os setores 40 e 41 na margem esquerda, compreendendo um percentual de aproximadamente $8 \%$ do total de setores da área de estudo. Espacialmente, os setores se concentram no bairro Santo Antônio (região Sul) e na zona rural do município, com destaque para os bancos de areia localizados na margem direita do rio.

A concentração desses bancos de areia na zona rural do município tem relação com a quantidade de meandros, o que facilita a acumulação e o depósito de sedimentos. Ressaltase ainda o fato do rio Parnaíba barrar as águas do Poti, e, desse modo, favorecer o aumento da lâmina d'água e a aparente diminuição de bancos de areia no rio Poti, principalmente na zona urbana.

Sobre a variável 7 (Qualidade da água), o IQA foi empregado como forma de diagnosticar a qualidade ambiental do rio Poti, considerando os parâmetros físicos, químicos e biológicos. No que se refere à classificação do rio Poti pela Resolução CONAMA $\mathrm{n}^{\circ} 357$ (BRASIL, 2005), ele foi enquadrado na classe 2 das águas doces, destinadas ao abastecimento humano, à proteção das comunidades aquáticas, à recreação de contato primário, à irrigação, à aquicultura e pesca.

Sobre a espacialização, os dados a serem discutidos serão os mais atuais e disponibilizados pelo LASAM/UFPI seguindo parâmetros de coleta como mencionam Oliveira e Silva (2014) e Medeiros, Silva e Lins (2018), conforme a seguinte classificação: "excelente" com IQA entre 80 e 100 (peso 1), "bom" com IQA entre 52 e 79 (peso 2), "regular" com IQA entre 37 e 51 (peso 3), "ruim" com IQA entre 20 e 36 (peso 4) e "muito ruim" com IQA entre 0 e 19 no IQA (peso 5). Os pesos foram atribuídos de acordo com a média aritmética das sazonalidades seca e chuvosa de 2016 junto aos setores censitários do entorno. Na análise da média aritmética foram encontradas apenas duas classes (pesos), "bom" e "regular".

Apenas os setores 13, 14, 15, 16, 17, 18, 19, 20 e 21 (margem esquerda) e 46, 47, 48 e 49 (margem direita) foram classificados como de IQA 
regular, portanto peso 3. Nestes setores encontramse parte dos bairros Água Mineral, Primavera, Morro da Esperança, Ininga e Fátima. Os demais setores foram classificados como de IQA "bom", consequentemente peso 2 .

Em termos quantitativos, $18 \%$ dos setores censitários tiveram classificação de IQA "regular", o que está intimamente relacionado não só com a dinâmica pluviométrica, como principalmente pelas características degradacionais do rio, tornando-o vulnerável frente à questão sanitária, despejo de lixo nas margens, extração mineral, desflorestamento da mata ciliar, formas de uso da terra, impermeabilização da terra e expansão urbana além de condicionantes naturais que são elementos fundamentais na qualidade hídrica (figura 08).

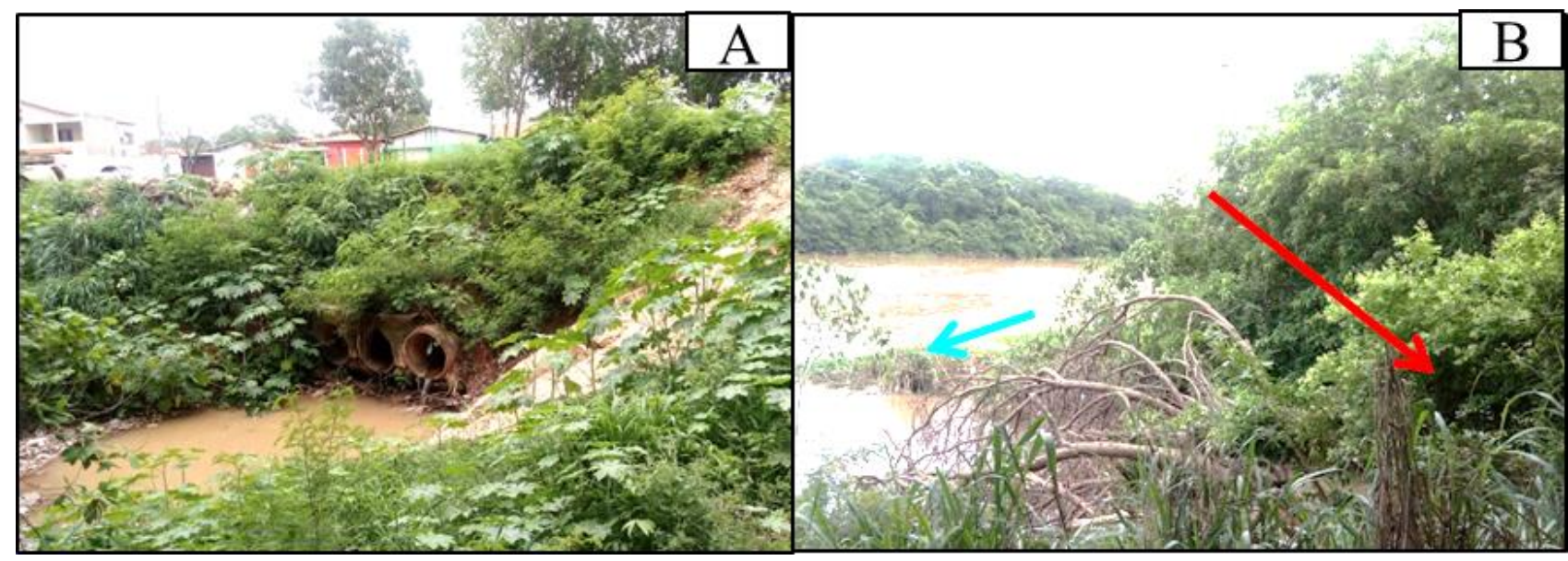

Figura 08 - Fontos de lançamento de esgoto in natura. Em A, setor 28; e em B, setor 19.

Na variável 8 (Lixo a céu aberto), na classe "pouco visível" foram identificados 26 setores censitários $(12,18,19,22,23,24,25,26,27,30$, $31,41,42,45,46,50,51,52,55,56,57,68,69,70$, 71 e 72) situados nos seguintes bairros: Embrapa, Primavera, Porenquanto, Cabral, Frei Serafim, Ilhotas, Cristo Rei, Santa Rosa, Zoobotânico, Ininga, Jóquei, Noivos, São Raimundo, Beira Rio e os setores censitários da zona rural (figura 09A).

Classificados como de visibilidade do lixo em alguns pontos, foram identificados 31 setores censitários $(2,3,6,7,8,9,10,11,13,14,15,20$, $21,32,33,34,37,38,39,40,43,44,47,48,49,53$, $54,58,65,66$ e 67$)$ e fazem parte das seguintes áreas: bairros Poti Velho, Alto Alegre, São
Francisco, Mocambinho, Água Mineral, Morro da Esperança, Três Andares, Santo Antônio, Aroeiras, Pedra Mole, Fátima, São João, Tancredo Neves, São Sebastião e Bom Princípio, abarcando todas as regiões administratativas da cidade (figura 09B).

Sobre a classe "facilmente visível" foram identificados um total de 15 setores censitários (1, $4,5,16,17,28,29,35,36,59,60,61,62,63$ e 64$)$ abarcando áreas dos seguintes bairros que margeiam o rio Poti: Olarias, Poti Velho, Água Mineral, Ilhotas, Catarina, Comprida, Extrema, Redonda e Parque Poti. Nessa classe foram encontrados setores localizados nas regiões Centro-Norte, Sul e Sudeste, com um predomínio desta primeira (figura 09C). 


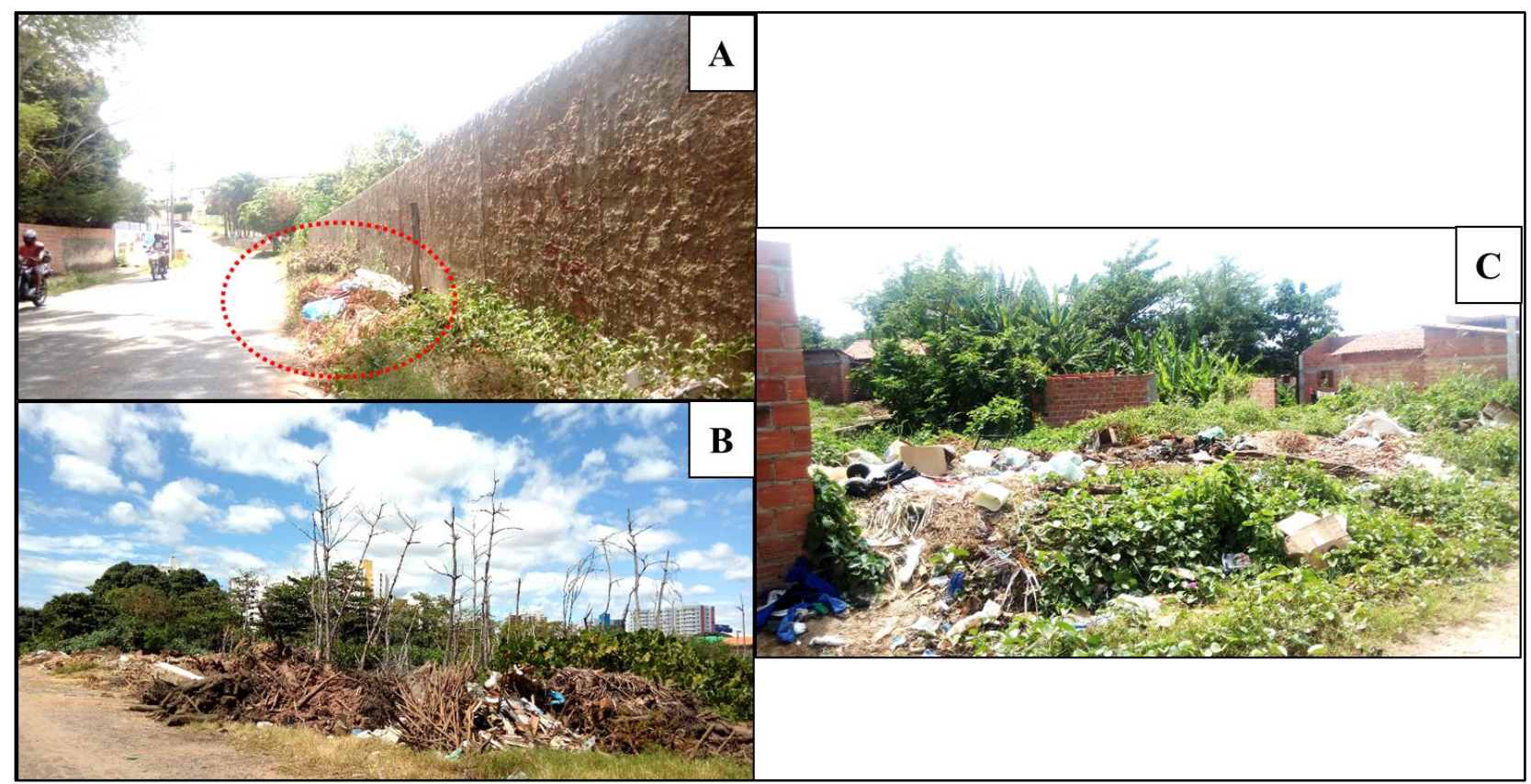

Figura 09 - Pontos de descarte de lixo. Em A, setor censitário 31; em B, setor 48; e em C, setor 28

As ameaças relacionadas à problemática de

lixo vão desde a poluição do solo, da água e do ar à concentração de vetores e doenças. Soma-se ainda o fato de que, além de contribuir para o déficit da qualidade ambiental, há diminuição da qualidade de vida da população, há danos paisagísticos e riscos de aumento do agravamento de inundações e alagamentos, além do transporte do lixo pela água e o entupimento de bueiros.

Apesar da existência de diversas formas de destinar esses materiais, a área de estudo apresenta carências a esse respeito, seja no depósito deliberado de lixo a céu aberto, seja na atuação da limpeza pública e presença de transportes para a sua coleta. Em nível percentual, 36\% dos setores censitários foram categorizados como de lixo "pouco visível", ante $43 \%$ e $21 \%$ das categorias "em alguns pontos" e "facilmente visível", respectivamente.

Sobre a variável Esgoto a céu aberto (variável 9), na classe "pouco visível" foram identificados 14 setores censitários (24, 25, 26, 27 , 41, 42, 47, 48, 49, 68, 69, 70, 71 e 72) situados nos seguintes bairros: Frei Serafim, Ilhotas, Santa Rosa e Fátima, além dos setores localizados na zona rural do município. Constata-se deste modo um serviço de esgotamento sanitário mais eficaz em poucos bairros da área de estudo, com destaque para o bairro de Fátima, região Leste, na margem direita, possuindo três setores (47, 48 e 49) identificados com pouca existência de esgoto a céu aberto (figura 10A)

Classificados como de visibilidade de esgoto a céu aberto em alguns pontos, foram identificados 26 setores censitários: 11, 12, 13, 14, $18,19,22,23,30,31,37,38,39,40,45,46,50,51$, $52,53,54,55,56,57,58$ e 59 .

Os mesmos estão dispostos nos seguintes bairros: Mocambinho, Embrapa, Água Mineral, Primavera, Porenquanto, Cabral, Cristo Rei, São Lourenço, Santo Antônio, Zoobotânico, Ininga, Jóquei, Noivos, São João, São Raimundo, Beira Rio, Tancredo Neves e Comprida (figura 10B).

Sobre a classe "facilmente visível" foram identificados 32 setores $(1,2,3,4,5,6,7,8,9,10$, $15,16,17,20,21,28,29,32,33,34,35,36,43,44$, $60,61,62,63,64,65,66$ e 67) em áreas dos seguintes bairros: Olarias, Poti Velho, Alto Alegre, São Francisco, Água Mineral, Morro da Esperança, Ilhotas, Três Andares, Catarina, Aroeiras, Pedra Mole, Extrema, Redonda, Parque Poti, São Sebastião e Bom Princípio, localizados em todas as regiões administrativas, com destaque para aqueles setores localizados na região Sudeste (figura 10C). 


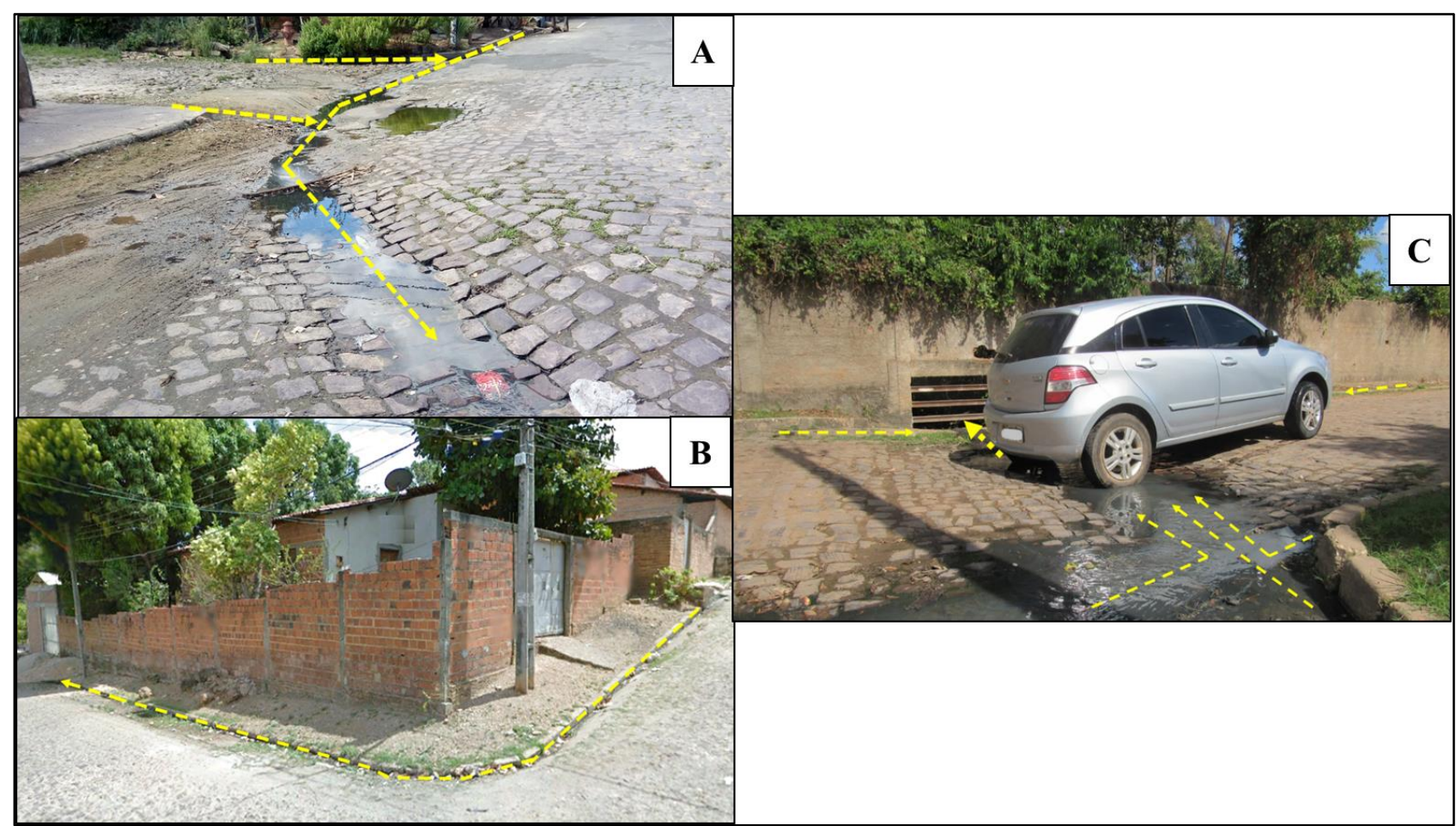

Figura 10 - Esgoto a céu aberto. Em A, setor 47; em B, 13; e em C, setor 63.

Percentualmente as classes dessa variável indicaram 19\% dos setores com classe "pouco visível", 36\% "em alguns pontos" e 45\% como "facilmente visível". Conclui-se com estes dados que a cobertura do esgotamento sanitário de Teresina é irrisória diante do tamanho da população e da cidade, e, principalmente dada a necessidade dessa infraestrutura com vista a melhoria de vida e da saúde das populações urbanas.

De acordo com a AGESPISA, na área de estudo apenas cinco bairros (Ininga, Fátima, Jóquei, Noivos e São João) que correspondem a parte dos setores 46, 47, 48, 49, 50, 51, 52 e 53, são beneficiados com esgotamento sanitário enquanto cerca de 25 bairros da área estão desprovidos de saneamento, estando previsto em projetos para construção o atendimento a apenas mais seis bairros na área de estudo, são eles: Primavera, Morro da Esperança, Porenquanto, Cabral, Ilhotas e Três Andares.

Tais dados podem ser relacionados com a qualidade da água do referido rio, principalmente a montante dos bairros com inexistência de esgotamento deixando as pessoas já vulneráveis socialmente expostas a riscos de saúde e problemas na qualidade de vida ficando evidente segundo Carmo e Guizardi (2018) que o meio (inclue-se aqui a dimensão ambiental) penetra no social.

$\mathrm{Na}$ variável 10 (Inundação), por meio da análise interpretativa da Carta de Suscetibilidade a Movimentos Gravitacionais de Massa e Inundação elaborada pelo Serviço Geológico Brasileiro (CPRM) foi possível identificar na área de estudo, os setores que possuem riscos de inundação e consequente vulnerabilidades ambientais a esse fenômeno.

$\mathrm{Na}$ classe de susceptibilidade "alta" de inundação (peso 3) foram identificados 62 setores censitários, distribuídos nas margens direita (42, $43,44,45,47,48,49,50,51,52,53,54,55,56,57$, $58,59,60,61,62,63,64,65,66,67$ e 70$)$ e esquerda $(1,2,3,4,5,6,7,8,9,10,11,12,13,14$, $15,16,17,18,19,20,21,22,23,24,25,26,27,28$, $29,30,31,32,33,34,35,36$ e 37). Logo, pela grande quantidade, há de se relacionar a espacialização dos mesmos, no que se refere às regiões administrativas de Teresina, todas (CentroNorte, Sul, Sudeste, Leste e Rural) possuem setores censitários enquadrados na categoria de alta susceptibilidade a inundação.

Os setores estão localizados nos seguintes bairros: Olarias, Poti Velho, Alto Alegre, São Francisco, Mocambinho, Embrapa, Água Mineral, Primavera, Morro da Esperança, Porenquanto, Cabral, Frei Serafim, Ilhotas, Cristo Rei, Três Andares, Catarina e São Lourenço (todos na margem esquerda), além de Santa Rosa, Aroeiras, Pedra Mole, Zoobotânico, Fátima, Jóquei, Noivos, São João, São Raimundo, Beira Rio, Tancredo Neves, Comprida, Extrema, Redonda, Parque Poti, São Sebastião, Bom Princípio e um setor na zona rural (todos na margem direita). 
$\mathrm{Na}$ classe "média" estão trechos com relevo de planícies aluviais, com amplitudes e declividades baixas e altura entre 6 e $10 \mathrm{~m}$ em relação ao nível da drenagem fluvial. Quanto ao aspecto pedológico, são terrenos argilo-arenosos, drenados e com nível subterrâneo raso a pouco profundo, caracterizados como solos hidromórficos e não hidromórficos.

Foram identificados sete setores censitários, na margem direita (44, 46, 68 e 69) distribuídos nos bairros Pedra Mole, Ininga e dois setores na zona rural, e na margem esquerda (38, 39 e 40) localizados no bairro Santo Antônio. E, assim como as outras classes, detém características no que se refere a declividade e altura sobre o nível da drenagem fluvial.

Na classe "baixa" as características são as seguintes: a) relevo de colinas com rios nas áreas de entalhamento fluvial; b) amplitudes e declividades baixas; c) terrenos areno-siltosos, drenados e com nível d'água subterrâneo pouco profundo; d) altura acima de $6 \mathrm{~m}$ em relação ao nível da drenagem fluvial; e e) solos não hidromórficos. Sobre os solos hidromórficos, conforme Nascimento, Lani e Zoffoli (2013) e Pinheiro et al (2016), estes constituem características específicas, de modo que refletem o ambiente de drenagem deficiente e a saturação (por água) na maior parte do tempo.

Foram identificados três setores censitários, a saber: 41 (margem esquerda) e os setores 71 e 72 (margem direita). Salienta-se que os mesmos estão localizados na zona rural de Teresina e, o seu grau de inundação baixa está relacionado com a altura do leito menor para as margens, além da própria característica pedológica e de drenagem.

Dessa forma, $88 \%$ dos setores censitários estão na classe de "alta" inundação. A figura 11 apresenta, o mapa de vulnerabilidade ambiental considerando a variável susceptibilidade a inundações da área de estudo.

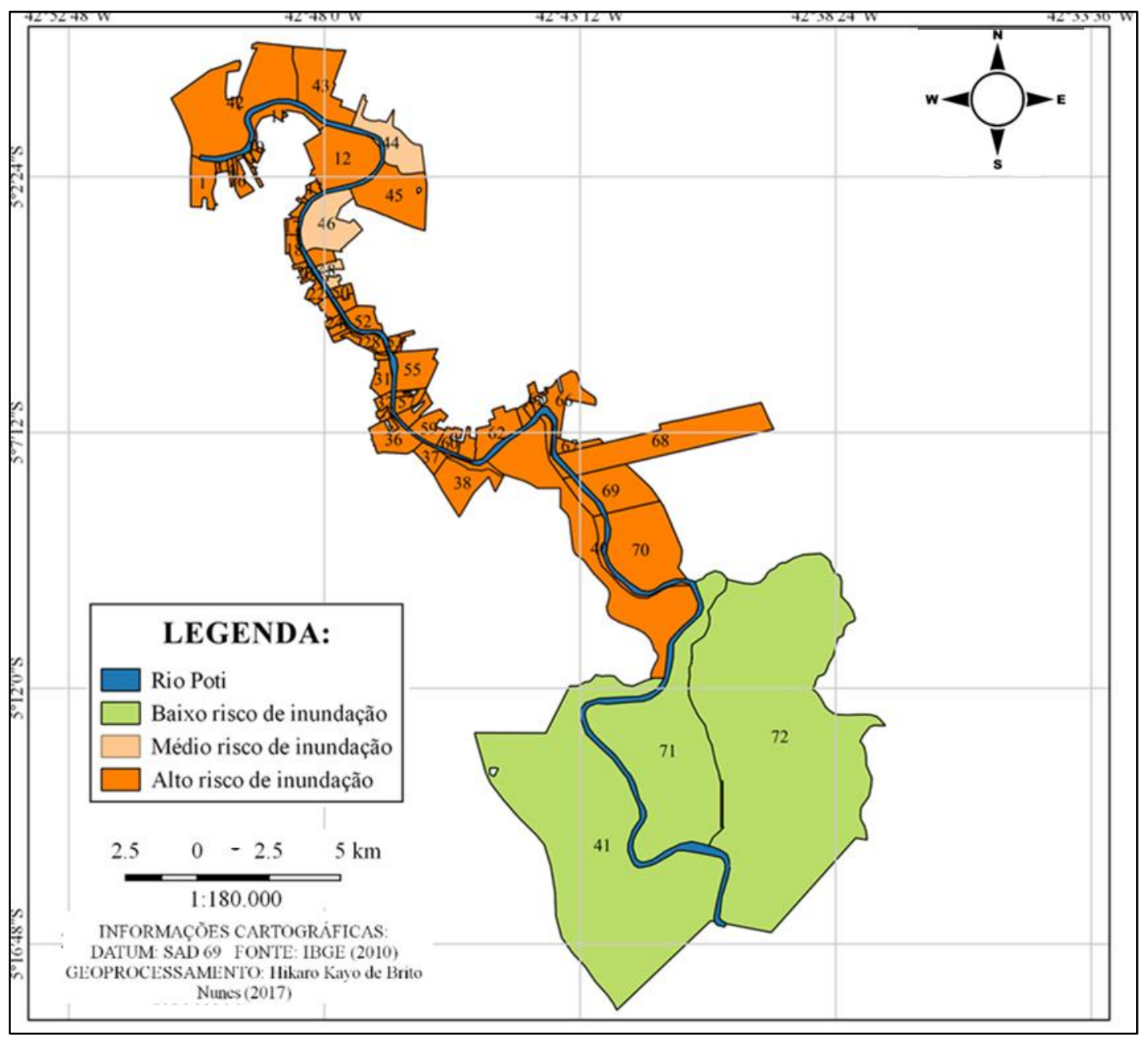

Figura 11 - Espacialização da vulnerabilidade à inundação

A medida que o rio Poti adentra o espaço urbano de Teresina a vulnerabilidade a inundações é intensificada. Isso deve-se ao fato principalmente da alta concentração de edificações nas áreas 
ribeirinhas, além do fenômeno de represamento das águas do Poti pelo rio Parnaíba, intensificando os riscos já existentes nos setores 1 e 42 .

$\mathrm{Na}$ variável que trata sobre alagamento (variável 11), em estudo realizado pela Assistência Militar/Defesa Civil do município de Teresina são monitorados aproximadamente 52 áreas que, quando do acontecimento de intensa precipitação pluviométrica associada a drenagem urbana deficitária há o acometimento de alagamentos na área. Nessa variável do IVA os setores foram agrupados em duas classes com seus respectivos pesos quando do risco de alagamento "presente" (peso 1) e "ausente" (peso 0). Na discussão que se segue será aborda a classe de risco "presente" de alagamento.

A variável alagamento é um reflexo de um somatório de elementos como: uso, ocupação e cobertura da terra, declividade, impermeabilização do solo, intensidade pluviométrica, descarte de lixo em locais inadequados, má qualidade ambiental de espaços urbanos, carência da drenagem urbana, dentre outros. Sobre as consequências, pode-se citar as seguintes: danos a características fisiográficas, transporte de lixo/sujeira para rios e lagoas, contaminação/poluição e ameaça à saúde pública.

$\mathrm{Na}$ área de estudo foram identificados 31 setores censitários que possuem o risco de alagamento, são eles: 1, 2, 3, 4, 5, 6, 7, 13, 14, 15, $16,17,18,19,20,21,22,26,27,28,29,32,33,34$, 35,36 (localizados na margem esquerda do rio Poti) e 50, 51, 52, 65 e 66 (localizados na margem direita do Poti). Os bairros que estão inseridos são: Olarias, Poti Velho, Alto Alegre, Água Mineral, Primavera, Morro da Esperança, Porenquanto, Ilhotas, Três Andares, Catarina, Jóquei, Noivos e São Sebastião.

Diante da problemática, a periculosidade e vulnerabilidade da área de estudo à ocorrências de alagamentos, tornou-se necessário um levantamento da probabilidade temporal $\mathrm{e}$ suscetibilidade espacial desta variavel que é exposta na figura 12.

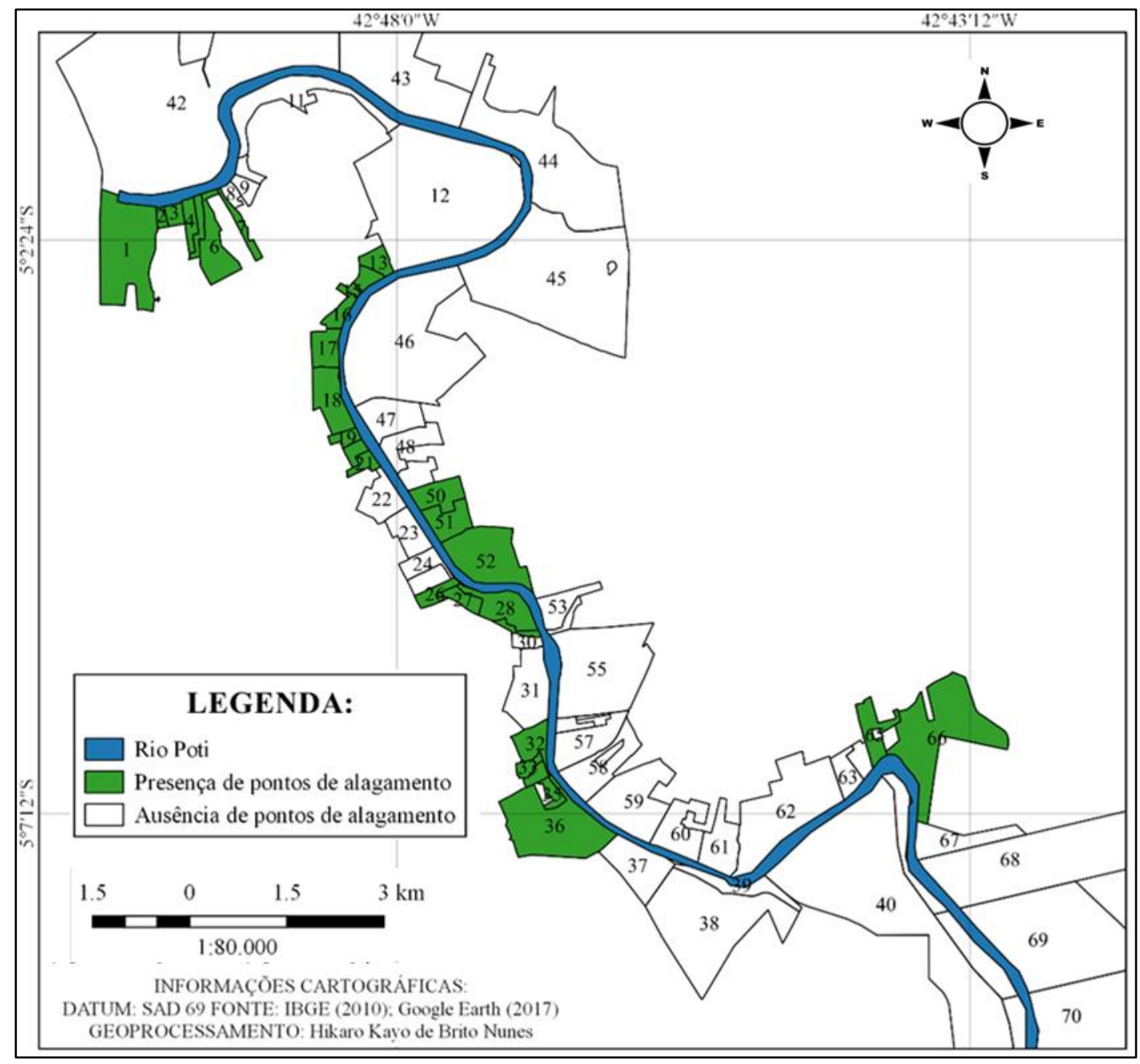

Figura 12 - Mapa de espacialização dos pontos de alagamento da área de estudo 
A presença de pontos de alagamento se concentra em maior parte na margem esquerda do rio Poti, e localizados na sua maioria na região Centro-Norte de Teresina, próximo a confluência do rio Parnaíba.

Para reconhecimento dos setores censitários que possuem movimentos de massas (variável 12) fez-se uso do mapeamento realizado pela CPRM, o mesmo utilizado na discussão da inundação em Teresina. Em CPRM (2014) as feições associadas a movimentos gravitacionais de massa e processos correlatos são os seguintes: a) ravina indicativa de suscetibilidade local/pontual decorrente de processos erosivos que podem induzir movimentos gravitacionais de massa; b) área úmida e; c) depósito de acumulação de pé de encosta (colúvio) suscetível a movimentação lenta (rastejo) ou rápida (deslizamento).

No presente estudo essa variável foi abordada em dois grupos, movimentos de massa "presente" e "ausente", com os pesos 1 e 0 , respectivamente. Nesse sentido, a discussão centrará atenções nos setores que obtiveram peso 1 , 26 setores censitários no total, perfazendo $36 \%$ do total de setores da área de estudo. Os setores onde há movimento de massa são: $01,12,18,37,39,40$ e 41 (margem esquerda) e $42,43,44,46,55,59$, $60,61,62,63,64,65,66,67,68,69,70,71$ e 72 (margem direita) localizados nos bairros: Olarias,
Embrapa, Primavera, São Lourenço, Santo Antônio e parte da zona rural, bem como Santa Rosa, Pedra Mole, Aroeiras, Ininga, São Raimundo, Comprida, Extrema, Redonda, Parque Poti, São Sebastião, Bom Princípio e em setores da zona rural.

Constatou-se uma maior concentração de setores com movimentos de massa localizados na zona rural e na margem direita do Poti. Esses movimentos de massa ocasionam a movimentação de rochas ou sedimentos na superfície, tratando-se assim de um processo geomorfológico em que há o depósito de materiais em áreas mais baixas.

É necessário destacar ainda que no setor 42 foi encontrada ravina indicativa de suscetibilidade decorrentes de processo erosivo e de atividade de extração mineral. Sobre as áreas alagadas, constatou-se uma concentração maior no encontro dos rios Poti e Parnaíba e em alguns meandros localizados principalmente no bairro São Sebastião (setores 65 e 66) e setor 70 .

\section{Considerações sobre o Índice de Vulnerabilidade Ambiental (IVA)}

Conforme resultados expressos na Tabela 02 constata-se que 24 dos 72 setores foram categorizados como de vulnerabilidade ambiental "Alta", seguido de 27 setores com vulnerabilidade "Média" e 21 setores com IVA "Baixa.

\begin{tabular}{|c|c|c|c|c|c|c|c|c|}
\hline SETORES & VALOR & CLASSE & SETORES & VALOR & CLASSE & SETORES & VALOR & CLASSE \\
\hline 4 & 23 & ALTA & 8 & 20 & MÉDIA & 71 & 17 & MÉDIA \\
\hline 33 & 23 & ALTA & 9 & 20 & MÉDIA & 23 & 16 & BAIXA \\
\hline 35 & 23 & ALTA & 21 & 20 & MÉDIA & 30 & 16 & BAIXA \\
\hline 61 & 23 & ALTA & 42 & 20 & MÉDIA & 40 & 16 & BAIXA \\
\hline 62 & 23 & ALTA & 43 & 20 & MÉDIA & 44 & 16 & BAIXA \\
\hline 5 & 22 & ALTA & 59 & 20 & MÉDIA & 51 & 16 & BAIXA \\
\hline 29 & 22 & ALTA & 17 & 19 & MÉDIA & 55 & 16 & BAIXA \\
\hline 34 & 22 & ALTA & 19 & 19 & MÉDIA & 67 & 16 & BAIXA \\
\hline 1 & 21 & ALTA & 37 & 19 & MÉDIA & 70 & 16 & BAIXA \\
\hline 2 & 21 & ALTA & 53 & 19 & MÉDIA & 22 & 15 & BAIXA \\
\hline 3 & 21 & ALTA & 64 & 19 & MÉDIA & 38 & 15 & BAIXA \\
\hline 7 & 21 & ALTA & 65 & 19 & MÉDIA & 46 & 15 & BAIXA \\
\hline 10 & 21 & ALTA & 14 & 18 & MÉDIA & 56 & 15 & BAIXA \\
\hline 13 & 21 & ALTA & 26 & 18 & MÉDIA & 57 & 15 & BAIXA \\
\hline 15 & 21 & ALTA & 27 & 18 & MÉDIA & 58 & 15 & BAIXA \\
\hline 16 & 21 & ALTA & 47 & 18 & MÉDIA & 68 & 15 & BAIXA \\
\hline 18 & 21 & ALTA & 49 & 18 & MÉDIA & 69 & 15 & BAIXA \\
\hline 20 & 21 & ALTA & 52 & 18 & MÉDIA & 72 & 15 & BAIXA \\
\hline 28 & 21 & ALTA & 11 & 17 & MÉDIA & 31 & 14 & BAIXA \\
\hline 32 & 21 & ALTA & 24 & 17 & MÉDIA & 41 & 14 & BAIXA \\
\hline 36 & 21 & ALTA & 25 & 17 & MÉDIA & 45 & 14 & BAIXA \\
\hline 60 & 21 & ALTA & 39 & 17 & MÉDIA & 12 & 13 & BAIXA \\
\hline 63 & 21 & ALTA & 48 & 17 & MÉDIA & & & \\
\hline 66 & 21 & ALTA & 50 & 17 & MÉDIA & & & \\
\hline 6 & 20 & MÉDIA & 54 & 17 & MÉDIA & & & \\
\hline
\end{tabular}

Tabela 02 - Classificação do Índice de Vulnerabilidade Ambiental (IVA) por setor censitário

Com Alta vulnerabilidade ambiental estão os seguintes setores (em ordem numérica crescente): 1, 2, 3, 4, 5, 7, 10, 13, 15, 16, 18, 20,
$28,29,32,33,34,35,36,60,61,62,63$ e 66 , totalizando aproximadamente $33 \%$ dos setores da área de estudo, que obtiveram valores entre 21 e 23 
no IVA. Os mesmos são encontrados nos seguintes bairros: Olarias, Poti Velho, Alto Alegre, São Francisco, Água Mineral, Primavera, Morro da Esperança, Ilhotas, Três Andares, Catarina, Extrema, Redonda, Parque Poti e São Sebastião.

No IVA Médio foram idenficados 27 setores censitários totalizando $38 \%$ da área de estudo, a saber (em ordem numérica crescente): 6 , $8,9,11,14,17,19,21,24,25,26,27,37,39,42$, $43,47,48,49,50,52,53,54,59,64,65$ e 71 . As área de IVA médio localizam-se nos bairros: Alto Alegre, São Francisco, Mocambinho, Água Mineral, Primavera, Morro da Esperança, Frei Serafim, Ilhotas, São Lourenço, Santo Antônio, Santa Rosa, Aroeiras, Fátima, Jóquei, Noivos, São João, Comprida, Parque Poti, São Sebastião e um parte da zona rural localizada na margem direita do rio Poti.
No IVA Baixo foram idenficados 21 setores censitários totalizando $29 \%$ da área de estudo, a saber (em ordem numérica crescente): 12, $22,23,30,31,38,40,41,44,45,46,51,55,56,57$, $58,67,68,69,70$ e 72 . Os mesmos estão nos seguintes bairros: Embrapa, Porenquanto, Cabral, Cristo Rei, Santo Antônio, Pedra Mole, Zoobotânico, Ininga, Jóquei, São Raimundo, Beira Rio, Tancredo Neves, Bom Princípio e 5 setores localizados na zona rural (um na margem esquerda e 4 na margem direita).

De forma sinóptica há que se considerar a espacialização da população e das referidas classes de IVA conforme gráfico 01. Do universo de moradores da área, aproximadamente $44 \%$ estão expostos a vulnerabilidade ambiental média, seguido de $41 \%$ e $15 \%$ em IVA alto e baixo, respectivamente.

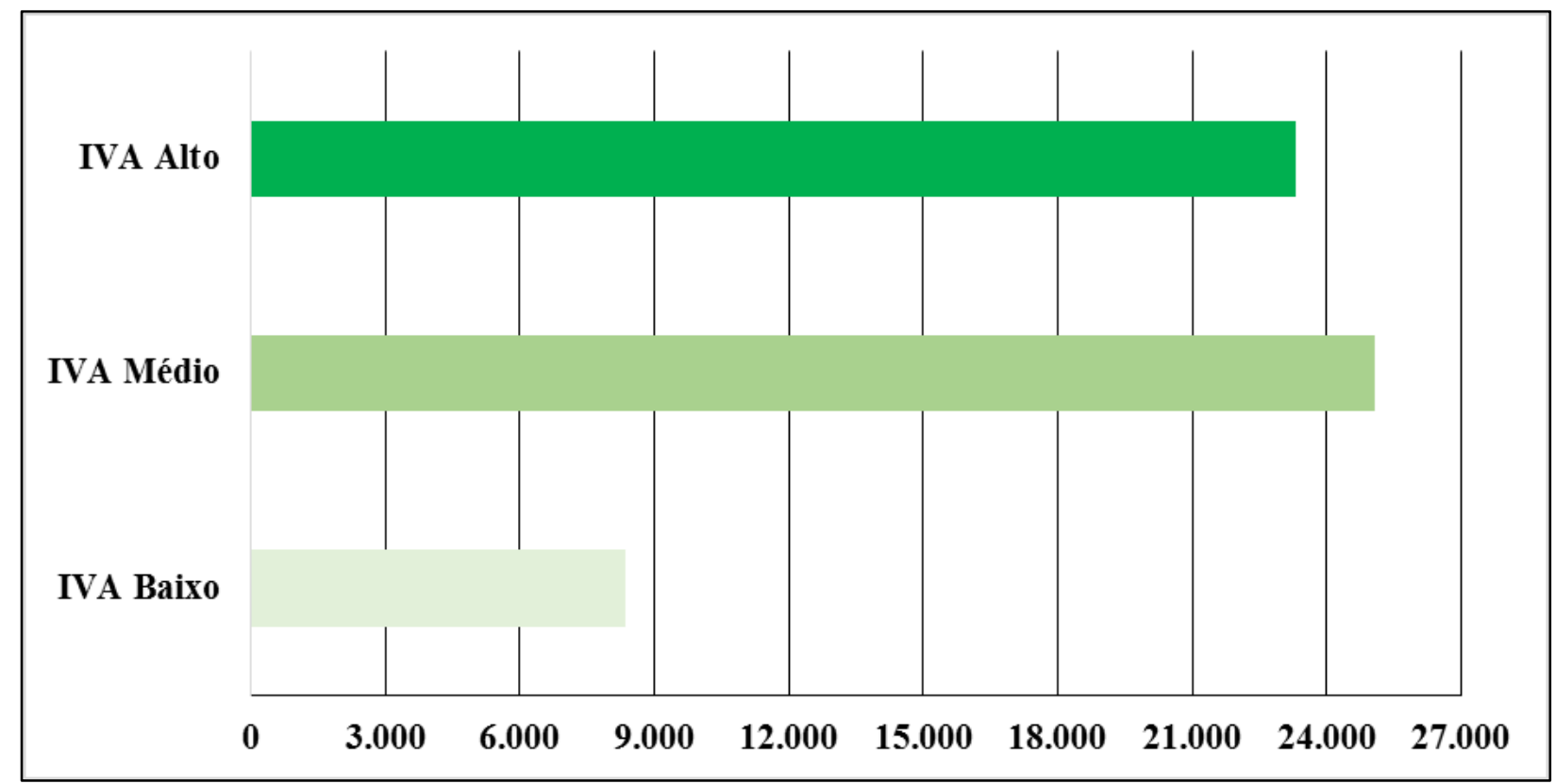

Gráfico 01 - Quantidade de pessoas expostas a problemas e riscos ambientais por classe de IVA

A figura 13 apresenta a síntese da espacialização do Índice de Vulnerabilidade Ambiental (IVA) dos setores censitários estudados.

$\mathrm{Na}$ área de estudo os maiores índices de IVA estão localizados espacialmente em trecho na região Sudeste de Teresina (concentrados entre os setores 60 e 66) e na região Centro-Norte, concentrados entre os setores 1 e 10, próximo a confluência com o rio Parnaíba e detentores de baixa cobertura vegetal, o que auxilia na intensificação dos riscos e vulnerabilidades ambientais nestes trechos.

Este diagnóstico das áreas mais vulneráveis ambientalmente poderá auxiliar na criação e aplicação de estratégias públicas e privadas com vistas a melhoria da qualidade ambiental da área. Sobre isso, Assis e Oliveira (2013) e Pechincha e Zaidan (2015) argumentam que os problemas ambientais não estão restritos como consequência da antropização sobre a natureza, e que os mesmos estão intimamente relacionados ao próprio espaço construído e espaço de vivências da sociedade.

Desse modo, ao se representar a cidade e as condições ambientais nela entalhada, se associa as questões sociais e físicas, e ratifica a necessidade de se garantir a qualidade de vida humana. 


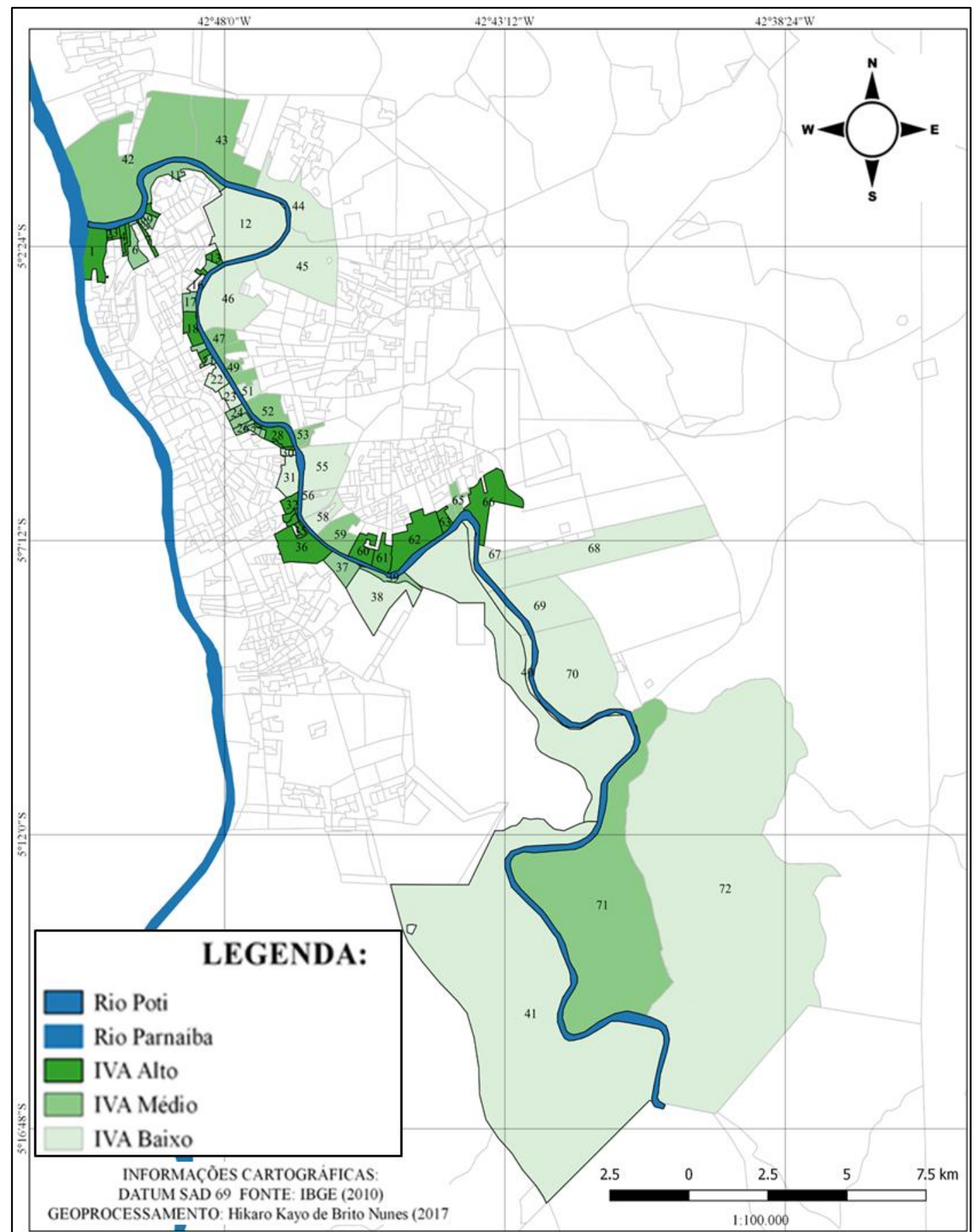

Figura 13 - Mapa de vulnerabilidade ambiental da área de estudo

\section{Considerações finais}

A cartografia da vulnerabilidade ambiental permitiu inferir alguns pontos que auxiliaram na interpretação e compreensão da problemática da área. Sobre os resultados do IVA, 21 setores foram classificados na classe "Baixa" (15\% da população expostas a riscos e problemas ambientais), 27 setores na classe "Média" ( $44 \%$ da população) e 24 setores censitários categorizados em IVA Alto (41\% da população).

As variáveis que conferiram o maior grau de vulnerabilidade ambiental aos setores censitários foram: cobertura vegetal, proximidade com corpos hídricos, adensamento populacional/residencial, esgoto a céu aberto e lixo a céu aberto. As mesmas estão intimamente relacionadas ao processo degradacional ambiental, e ao consequente desencadeamento de riscos 
ambientais, que, somados e inter-relacionados, intensificam a vulnerabilidade da área.

\section{Agradecimentos}

À Coordenação de Aperfeiçoamento de Pessoal de Nível Superior (CAPES) pela concessão de bolsa durante o curso, sendo esta de fundamental importância para a realização e concretização da pesquisa, e ao Laboratório de Saneamento (LASAM) do Centro de Tecnologia (CT) da Universidade Federal do Piauí (UFPI).

\section{Referências}

Alcântara, V. S.; Strauch, J. C. M.; Ajara, C. 2013. Metodologia para análise da vulnerabilidade socioambiental: estudo de caso na macrorregião da Costa Verde. Revista Brasileira de Cartografia 3, 555-570.

Assis, S. S.; Oliveira, H. C. M. 2013. Qualidade ambiental urbana: avaliação da área central da cidade de Ituiutaba (MG). GeoAtos 2, 26-41.

BRASIL, 2005. Resolução 357 de 17 de março de 2005. Brasília, 2005.

Carmo, M. E.; Guizardi, F. L. 2018. O conceito de vulnerabilidade e seus sentidos para as políticas públicas de saúde e assistência social. Cadernos de Saúde Pública 34, 1-14. Disponível: http://dx.doi.org/10.1590/0102-311x00101417. Acesso: 20 set. 2017.

CPRM. Serviço Geológico do Brasil, 2014. Carta de Suscetibilidade a Movimentos Gravitacionais de Massa e Inundação. Brasília.

Cremonez, F. E. et al. 2014. Avaliação de impacto ambiental: metodologias aplicadas no Brasil. REMOA 13, 3821-3830. Disponível: http://dx.doi.org/10.5902/2236130814689.

Acesso: 20 set. 2017.

França, L. C. J. et al. 2018. Caracterização da cobertura vegetal em uma bacia hidrográfica do Piauí por meio de dois métodos. BIOFIX Scientific Journal 3, 62-71. Disponível: http://dx.doi.org/10.5380/biofix.v3i1.57461. Acesso: 20 set. 2017.

Freitas, M. I. C.; Cunha, L. 2013. Cartografia da vulnerabilidade socioambiental: convergências e divergências a partir de algumas experiências em Portugal e no Brasil. Urbe - Revista Brasileira de Gestão Urbana 5, 15-31. Disponível:

http://dx.doi.org/10.7213/urbe.7783. Acesso: 20 set. 2017.

IBGE. Instituto Brasileiro de Geografia e Estatística, 2010. Censo Demográfico de 2010. Rio de Janeiro.

IBGE. Instituto Brasileiro de Geografia e Estatística, 2013. Manual técnico de uso da terra. Rio de Janeiro.

IBGE. Instituto Brasileiro de Geografia e Estatística, 2017. Agregados por setores censitários dos resultados de universo. Disponível em:< http://www.ibge.gov.br/home/estatistica/popul acao/defaulttab_agregado.shtm. Acesso: 20 set. 2017.

Lima, G. C. et al. 2013. Avaliação da cobertura vegetal pelo índice de vegetação por diferença normalizada (IVDN). Revista Ambiente \& Água $\quad 8, \quad 204-214$. Disponível: http://dx.doi.org/10.4136/ambi-agua.959.

Acesso: 20 set. 2017.

Lourenço, J. C. et al. 2013. Identificação de fatores de vulnerabilidade ambiental na Floresta do Louzeiro em Campina Grande-PB. Polêmica 12, 274-283. Disponível: https://doi.org/10.12957/polemica.2013.6429. Acesso: 20 set. 2017.

Medeiros W. M. V; Silva, C. E.; Lins, R. P. M. 2018. Avaliação sazonal e espacial da qualidade das águas superficiais da bacia hidrográfica do rio Longá, Piauí, Brasil. Revista Ambiente e Agua 13, 1-17. Disponível: http://dx.doi.org/10.4136/ambi-agua.2054. Acesso: 20 set. 2017.

Medeiros, C. N.; Souza, M. J. N., 2016. Metodologia para mapeamento da vulnerabilidade socioambiental: caso do município de Caucaia, estado do Ceará. REDE - Revista Eletrônica do PRODEMA 10, 54-73.

Moraes, B. C. et al., 2016. O Método Expedito como estratégia de avaliação qualitativa dos níveis de vulnerabilidade em ambientes da zona urbana de Teresina, Piauí. Revista Equador 5, 500-517. 
Morais, L. G. B. L.; Melo, J. A. B. 2013. Pensando a relação sociedade-natureza na geografia: apontamentos para a geografia socioambiental. Caminhos de Geografia 14, 22-29.

Nascimento, P. C.; Lani, J. L; Zoffoli, H. J. O. 2013. Caracterização, classificação e gênese de solos hidromórficos em regiões litorâneas do Estado do Espírito Santo. Científica 41, 82-93. Disponível: http://dx.doi.org/10.15361/19845529.2013v41n1p82-93. Acesso: 20 set. 2017.

Oliveira, L. N.; Silva, C. E. 2014. Qualidade da água do rio Poti e suas implicações para atividades de lazer em Teresina-PI. Revista Equador 3, 128-147.

Pechincha, M. G. H.; Zaidan, R. T. 2016. Análise da qualidade ambiental urbana através de ambiente SIG: uma aplicação no município de Juiz de Fora - MG. Revista Brasileira de Cartografia 68, 1-17.

Pfaltzgraff, P. A. S (Org), 2010. Geodiversidade do estado do Piauí. CPRM, Recife.

Pinheiro, H. S. K. et al. 2016. Ferramentas de pedometria para caracterização da composição granulométrica de perfis de solos hidromórficos. Pesquisa Agropecuária Brasileira 51, 1326-1338. Disponível: 10.1590/S0100-204X2016000900032. Acesso: 20 set. 2017.

Ribeiro, V. M.; Vóvio, C. L. 2017. Desigualdade escolar e vulnerabilidade social no território. Educar em Revista, 2, 71-87. Disponível: http://dx.doi.org/10.1590/0104-4060.51372. Acesso: 20 set. 2017.

Santos, J. O. 2015. Relações entre fragilidade ambiental e vulnerabilidade social na susceptibilidade aos riscos. Mercator 14, 75-90. Disponível: $\quad$ 10.4215/RM2015.1402. 0005 . Acesso: 20 set. 2017.

Silva, D. C. C. et al. 2017. Metodologia para análise do potencial de degradação dos recursos hídricos em bacias hidrográficas. Caderno de Geografia 27, 455-466. Disponível: https://doi.org/10.5752/p.2318-

2962.2017v27n50p455. Acesso: 20 set. 2017.

Suertegaray, D. M. A., 2015. Geografia, ambiente e território. Revista da Casa da Geografia de Sobral 17, 128-144.

Suertegaray, D. M. A., 2017. Debate contemporâneo: Geografias ou Geografia? Fragmentação ou Totalização? GEOgraphia 19, 95-102.

Viana, B. A. S. 2015. Conflitos socioambientais associados à exploração de massará em Teresina-PI. Sapiência 12, 14-14.

Viana, B. A. S. et al. 2015. Estratigrafia e análise granulométrica das camadas de massará e seixos em Teresina-PI. Revista Equador 4, 1-7.

Vieira, C. I. P.; Viana, B. A. S. 2016. Áreas de extração mineral para construção civil em Teresina - PI: aspectos físicos e seus impactos socioambientais. Revista Equador 5, 99-119. 